\title{
EDUARDO ZLOTNIK
}

Parâmetros de ressonância magnética da pelve como fatores

preditivos de resposta do leiomioma uterino à embolização arterial

\author{
Tese apresentada à Faculdade de Medicina da \\ Universidade de São Paulo para obtenção do título de \\ Doutor em Ciências
}

Programa: Obstetrícia e Ginecologia

Orientador: Dr. Marcos de Lorenzo Messina

\section{São Paulo}

2012 
Dados Internacionais de Catalogação na Publicação (CIP)

Preparada pela Biblioteca da

Faculdade de Medicina da Universidade de São Paulo

Creprodução autorizada pelo autor

\section{Zlotnik, Eduardo}

Parâmetros de ressonância magnética da pelve como fatores preditivos de resposta do leiomioma uterino à embolização arterial / Eduardo Zlotnik. --- São Paulo, 2012.

Tese(doutorado)--Faculdade de Medicina da Universidade de São Paulo.

Programa de Obstetrícia e Ginecologia.

Orientador: Marcos de Lorenzo Messina.

Descritores: 1.Mioma 2.Embolização da artéria uterina 3.Imagem por ressonância magnética

USP/FM/DBD-115/12 


\section{DEDICATÓRIA}

À Silvia, minha companheira e cúmplice. Fundamental nesta jornada e senhora do tempo.

Aos meus filhos Mira, Marcelo e Marcos, definição de amor incondicional.

Aos meus pais Milton e Eliane, meu respeito e gratidão pela paciência e amor.

À minha mãe Mira, sempre presente, cujos ensinamentos e exemplos se perpetuam. 


\section{AGRADECIMENTOS}

À Disciplina de Ginecologia do Departamento de Obstetrícia e Ginecologia do Hospital das Clínicas da Faculdade de Medicina da Universidade de São Paulo, na pessoa do Professor Doutor Edmund Chada Baracat, nome importante para ginecologia brasileira e de quem tive o privilégio de receber o incentivo, colaboração e revisão deste trabalho.

Ao Instituto de Responsabilidade Social da Sociedade Beneficente Israelita Brasileira Hospital Albert Einstein na pessoa do presidente Doutor Claudio Luiz Lottenberg, exemplo de abnegação ao trabalho. Incentivador do meu desenvolvimento pessoal, desde o início de minha carreira médica.

Ao Doutor Marcos de Lorenzo Messina, meu orientador e principal incentivador nesta pós-graduação, sempre com bons conselhos, um exemplo de dedicação e amizade. Humano, antes de médico e pesquisador.

Ao Doutor Claudio Schvartsman pelo incentivo fundamental desde o início.

Aos Doutores Nelson Wolosker pela cuidadosa revisão e Sidney Klajner pela paciência e conselhos neste período.

Ao Doutor Nilo Bozzini e a equipe do Setor do Mioma da Disciplina de Ginecologia do Departamento de Obstetrícia e Ginecologia do Hospital das Clínicas da Faculdade de Medicina da Universidade de São Paulo pelo apoio e a importante colaboração neste trabalho. 
Aos Doutores Felipe Nasser, Breno Affonso e equipe da Radiologia Vascular Intervencionista do Hospital Israelita Albert Einstein pelo empenho, colaboração e desenvolvimento de toda equipe.

Ao Doutor Ronaldo Hueb Baroni e equipe do Setor de Ressonância Magnética do Departamento de Imagem do Hospital Israelita Albert Einstein pela essencial participação.

Ao Doutor Sérgio Podgaec, pela ajuda e fonte de inspiração e dedicação aos estudos.

Àqueles com quem trabalho e que sempre mostraram paciência com minhas ausências e excesso de compromissos, Ricardo Goldstein, Luiz Roberto Zitron, , Alessandra Bedin Bedin Ciminelli Rubino, Alexandre Selvaggio, Nilson Abrão Szylit, e à toda família Quarenta e Batista.

À Claudia Vieira, por toda a orientação e apoio fundamentais nesta caminhada.

Às pacientes, colaboradoras fundamentais para a realização deste estudo, meus sinceros agradecimentos. 


\section{SUMÁRIO}

\begin{tabular}{|c|c|c|}
\hline \multicolumn{3}{|c|}{ ista de Símbolos } \\
\hline \multicolumn{3}{|c|}{ Lista de Abreviaturas } \\
\hline \multicolumn{3}{|c|}{ Lista de Figuras } \\
\hline \multicolumn{3}{|c|}{ Lista de Tabelas } \\
\hline \multicolumn{3}{|c|}{ Resumo } \\
\hline \multicolumn{3}{|c|}{ Summary } \\
\hline 1 & INTRODUÇÃO.. & 1 \\
\hline 1.1 & Diagnóstico......... & 4 \\
\hline 1.2 & Tratamento.. & 5 \\
\hline 0 & OBJETIVOS & \\
\hline 2.1 & Geral. & \\
\hline 2.2 & Específico. & \\
\hline 3 & PACIENTES E MÉTODO. & 1 \\
\hline 3.1 & Caracterização das pacientes.. & 2 \\
\hline 3.1.1 & Critérios de Inclusão... & 13 \\
\hline 3.1 .2 & Critérios de Exclusão.... & 4 \\
\hline 3.2 & Dinâmica do estudo...... & 15 \\
\hline 3.3 & 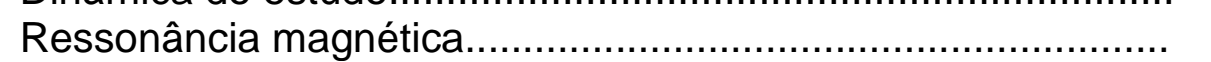 & 9 \\
\hline 3.4 & EAU-técnica. & 25 \\
\hline 3.5 & 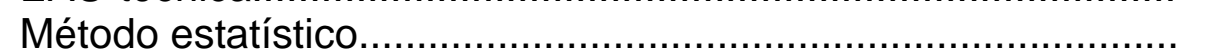 & 30 \\
\hline 4 & RESULTADOS & \\
\hline 4.1 & $\begin{array}{l}\text { Análise das medidas do útero antes e após embolização por } \\
\text { paciente }\end{array}$ & 33 \\
\hline 4.2 & $\begin{array}{l}\text { Análise das medidas antes e após embolização pelos nódulos } \\
\text { de leiomioma. }\end{array}$ & 33 \\
\hline 4.2 .1 & Caracterização dos nódulos de leiomioma................... & \\
\hline 4.2.2 & Medidor dos nódulos de leiomioma.... & \\
\hline 4.2.3 & Análise da redução percentual do volume dos nódulos..... & \\
\hline 4.3 & 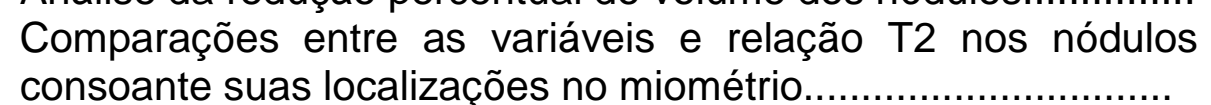 & \\
\hline 4.4 & Curva ROC para determinar ponto de corte.......................... & 42 \\
\hline 5 & DISCUSSÃO & \\
\hline 5.1 & O estudo......... & \\
\hline 5.2 & Ressonância magnética... & \\
\hline 5.3 & Leiomiomas. & \\
\hline 5.4 & Parâmetros radiológicos: valor em T2, relação T2 e relação PP. & \\
\hline 5.5 & Pontos de corte... & \\
\hline 5.6 & Relação da diminuição volumétrica com melhora clínica.............. & \\
\hline 5.7 & 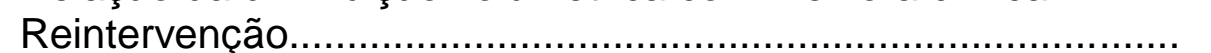 & \\
\hline 6 & CONCLUSÃO... & \\
\hline 7 & (2) & \\
\hline 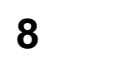 & 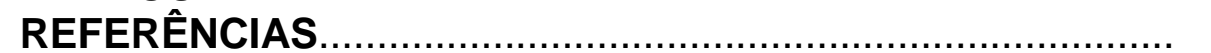 & \\
\hline
\end{tabular}




\title{
LISTA DE SÍMBOLOS
}

\author{
$\mathrm{mm} \quad$ Milímetro \\ $\mathrm{Kg} / \mathrm{m}^{2} \quad$ Quilograma por Metro Quadrado \\ $\mathrm{Cm}^{3} \quad$ Centímetro Cúbico \\ SI Signal Intensity ou Intensidade de Sinal \\ $\mathrm{ml} \quad$ Mililitro \\ $\mathrm{ml} / \mathrm{s} \quad$ Mililitros por Segundo \\ psi Pound Force per Square Inch ou Libra-Força por Polegada Quadrada \\ mcg Microgramas
}




\section{LISTA DE ABREVIATURAS}

USTV

EUA

$\mathrm{RR}$

IMC

RM

EAU

$\mathrm{GnRH}$

$\mathrm{HC}$

FMUSP

HIAE

SUS

TCLE

PP

RAVA

PCA

DP

3T

$\mathrm{ROC}$

AUC
Ultrassom Pélvico Transvaginal

Estados Unidos da América

Risco Relativo

Índice de Massa Corpórea

Ressonância Magnética da Pelve

Embolização da Artéria Uterina

Gonadotropin-Releasing Hormone ou Hormônio Liberador de Gonadotrofinas

Hospital das Clínicas

Faculdade de Medicina da Universidade de São Paulo

Sociedade Beneficente Israelita Brasileira Hospital Albert Einstein

Sistema Único de Saúde

Termo de Consentimento Livre e Esclarecido

Padrão de Perfusão do Contraste

Radiologia Vascular Intervencionista

Patient Continous Anesthesia ou Anestesia Contínua do Paciente

Desvio padrão

3-Tesla

Receiver Operator Characteristics

Área sob a Curva ou Area Under the Curve 


\section{LISTA DE FIGURAS}

Figura 1 Dinâmica do estudo, demonstrando as diversas fases do protocolo de atendimento e o número de pacientes

Figura 2 Ressonância magnética da pelve mostrando a mensuração do sinal em T2 $(215,76 \mathrm{SI})$ em área central de leiomioma intramural. $(\mathrm{SI}=$ medida da intensidade do Sinal)

Figura 3 Ressonância magnética da pelve mostrando a mensuração do sinal em T2 $(215,76 \mathrm{SI})$ em área central de leiomioma intramural. $(\mathrm{SI}=$ medida da intensidade do Sinal)

Figura 4 Ressonância magnética da pelve demonstrando as fases pré e pós contraste. Os leiomiomas apresentam impregnação heterogênea pelo meio de contraste paramagnético, semelhante à observada no miométrio, destacando-se áreas focais de hipocontrastações, compatíveis com necrose/degeneração

Figura 5 Redução percentual do volume dos nódulos (-40 a 100\%) ..... 35

Figura 6 Medidas de redução percentual do volume dos nódulos nas diferentes localizações no miométrio

Figura 7 Redução percentual do volume dos nódulos de acordo com seu tamanho $\left(\mathrm{cm}^{3}\right)$ antes do tratamento

Figura 8 Redução percentual do volume de acordo com o número de nódulos em cada útero

Figura 9 Curva ROC analisando a sensibilidade e especificidade da Relação T2 


\section{LISTA DE TABELAS}

Tabela 1 Idade, número de gestações, cor da pele, e volume uterino das pacientes submetidas a embolização da artéria uterina .....

Tabela 2 Comparação, pela ressonância magnética, entre os volumes uterino antes e após a embolização da artéria uterina.

Tabela 3 Caracterização, pela ressonância magnética, dos nódulos de
leiomioma, segundo a localização no miométrio e pelo seu volume dividido em tercis

Tabela 4 Descrição da presença de necrose nos nódulos comparando os momentos antes e após a embolização da artéria uterina ...

Tabela 5 Medidas do volume dos nódulos e valor do sinal em T2 antes e após a embolização da artéria uterina

Tabela 6 Resultados da análise univariada e multivariada - variável dependente: redução maior que $50 \%$.

Tabela 7 Relação T2 (nódulo/músculo em T2) nos leiomiomas nas diferentes localizações no miométrio.

Tabela 8 Relação PP nos leiomiomas nas diferentes localizações no miométrio. 


\section{RESUMO}

Zlotnik E. Parâmetros de ressonância magnética da pelve como fatores preditivos de resposta do leiomioma uterino à embolização arterial [tese]. São Paulo: Faculdade de Medicina, Universidade de São Paulo; 2012.

Os métodos minimamente invasivos têm sido cada vez mais utilizados para o tratamento do leiomioma e, a embolização da artéria uterina, tem se destacado como método seguro e efetivo. O objetivo deste estudo foi avaliar, pela ressonância magnética da pelve, os fatores preditores da diminuição dos leiomiomas de pacientes submetidos a embolização da artéria uterina. Métodos: Estudaram-se 50 mulheres sintomáticas com leiomioma uterino, na menacme, que foram submetidas a embolização da artéria uterina. Acompanhou-se, por meio da ressonância magnética o volume do útero e dos leiomiomas. Foram examinados 179 leiomiomas nestas pacientes, um mês antes e seis meses depois do procedimento. Resultados: Seis meses após o tratamento, a redução média do volume uterino foi de $38,91 \%$, enquanto os leiomiomas tiveram redução de $55,23 \%$. Nos leiomiomas submucosos e/ou com a relação nódulo/músculo em T2 mais elevada, a redução do volume foi ainda maior (maior que 50,00\%). Conclusões: As pacientes portadoras de leiomiomas e submetidas à embolização da artéria uterina apresentaram redução de volume dos nódulos 
superior a 50,00\%, à ressonância magnética, quando eram submucosos e/ou tinham uma relação nódulo/músculo em T2 mais elevada.

Descritores: mioma, embolização da artéria uterina, imagem por ressonância magnética. 


\section{SUMMARY}

Zlotnik E. Predictive factors of pelvic magnetic resonance in the response of arterial embolization of the uterine leiomyoma [thesis]. São Paulo: Faculdade de Medicina, Universidade de São Paulo; 2012.

Objective : Minimally invasive methods are being an alternative to treat leiomyomas, including the uterine artery embolization that has emerged as a safe and effective method. The aim of this study was to evaluate the magnetic resonance imaging predictors of decrease in leiomyomas of patients who underwent uterine artery embolization. Methods: This study followed 50 symptomatic premenopausal women with uterine leiomyoma who underwent uterine artery embolization. Treatment was accompanied by magnetic resonance imaging of both the volume of the uterus and the leiomyomas. We examined 179 leiomyomas in that 50 patients, one month before and six months after of the procedure. Results: Six months after treatment, the mean reduction in uterine was $38.91 \%$, while leiomyomas decreased by $55.23 \%$. In submucosal leiomyomas and/or with a higher node/muscle ratio in T2, the volume reduction was even higher (greater than 50.00\%). Conclusions: The patients with leiomyomas and underwent uterine artery embolization, showed reductions in the volume of nodes greater than $50,00 \%$, on the magnetic resonance imaging, when they were submucosal and / or had a higher node-to-muscle ratio in T2.

Keywords: Leiomyoma, uterine artery embolization, magnetic resonance imaging 


\section{1 - INTRODUÇÃO}

O leiomioma uterino é a neoplasia benigna mais comum do trato genital feminino e a mais frequente nas mulheres em idade reprodutiva. Anualmente, são realizados novos diagnósticos em $0,92 \%$ das mulheres (Cardozo et al., 2012).

São tumores monoclonais que se desenvolvem a partir das células miometriais. A sua etiopatogenia ainda não está totalmente estabelecida, mas é multifatorial e dela fazem parte as mutações herdadas e somáticas, hormônios esteróides, regulação dos fatores de crescimento e uma matriz extracelular ativa (Walker \& Stewart, 2005). É uma doença heterogênea de tal modo que os diferentes tipos de leiomiomas podem ter diversas etiologias (Stewart, 2001). Um cariótipo anormal é encontrado em $60 \%$ dos nódulos (Rein et al., 1991; Othman \& Al-Hendy, 2008).

No Brasil, em 2007, apenas 44.415 internações foram motivadas por leiomioma uterino, demonstrando provável subnotificação (Portal do Ministério da Saúde, 2011).

Aproximadamente seiscentas mil histerectomias são realizadas anualmente nos Estados Unidos (EUA), e destas 40,7\% são realizados devido aos leiomiomas. Além das histerectomias, cerca de vinte mil miomectomias são realizadas naquele país em virtude dos sintomas 
causados por essa doença (ACOG, 2009).

Em achados de ultrassom pélvico transvaginal (USTV), sua incidência varia de $30 \%$ em torno de 35 anos de idade, a $80 \%$ ao redor dos 50 anos (Parker, 2007). Apresenta prevalência de $77 \%$, considerando-se nódulos a partir de $2 \mathrm{~mm}$ em peças de histerectomia e, por ser na maioria dos casos, de pacientes assintomáticas, estima-se que a sua prevalência possa ser ainda maior (Cramer \& Patel, 1990).

Entre os fatores de risco, destacam-se (Schwartz, 2001; Parker, 2007):

- as mulheres de raça negra que apresentam um risco relativo (RR) de 9,4 em relação às brancas;

- as mulheres cuja menarca, quando anterior aos 11 anos, têm $R R$ de 2,4 em relação àquelas com menarca após os 13 anos;

- a história familiar, quando apresenta antecedente de leiomioma em parentes de primeiro grau aumenta o risco da doença em 4 a 5 vezes;

- as mulheres com o índice de massa corpórea (IMC) maior que $30 \mathrm{Kg} / \mathrm{m}^{2}$, possuem RR de 2,3 em relação àquelas com IMC menor que $25 \mathrm{Kg} / \mathrm{m}^{2}$.

Dentre os fatores considerados protetores destacam-se (Schwartz, 2001; Parker, 2007):

- o uso habitual de anticoncepcionais orais tem RR de 0,2 ; 
- as mulheres que tiveram a idade da primeira gestação entre 25 e 29 anos de idade apresentam proteção, quando comparada com mulheres abaixo dos 25 anos e acima dos 30 anos (RR de $0,7)$;

- o tabagismo acima de 19 anos (RR de 0,6).

Em relação às brancas, as mulheres negras têm o diagnóstico mais precoce ( $31 \times 37$ anos) e estas têm mais sintomas ( $30 \times 15 \%)$ o que pode ser justificado pelo maior número de polimorfismos (Day Baird et al., 2003; Othman \& Al-Hendy, 2008).

O tumor pode alcançar grandes dimensões, causando poucos sintomas e, do contrário, pequenos nódulos podem ocasionar exuberantes sintomas (Gambone et al., 1990). Apesar de mais que $70 \%$ das mulheres serem portadoras de leiomioma uterino apenas $25 \%$ dessas apresentam sintomas e necessitam de tratamento (Cramer \& Patel, 1990; Tulandi \& Salamah, 2010).

Quando sintomáticas, os principais achados clínicos são: fluxo menstrual excessivo, dismenorréia, dispareunia de profundidade e sintomas urinários como poliúria, disúria e urgência miccional (Wallach \& Vlahos, 2004). O sangramento uterino excessivo ou dor pélvica ocorrem em até $50 \%$ dos casos (Parker, 2007). Estes sintomas podem prejudicar a qualidade de vida da mulher e por isso a presença dos leiomiomas uterinos é uma indicação muito frequente de histerectomia (Pron et al., 2003; Haney, 2000). A qualidade de vida das mulheres com leiomiomas que necessitam de 
tratamento cirúrgico, é menor do que das mulheres com doenças crônicas pulmonares, artrite, hipertensão ou cardiopatias (Parker, 2012).

O leiomiossarcoma, tumor maligno de origem miometrial, é dificilmente distinguível do leiomioma, clinicamente ou mesmo por meio de exames de imagem. Representa apenas $0,1 \%$ dos tumores uterinos e devido a baixa ocorrência além da dificuldade na diferenciação clínica, os tumores uterinos são considerados, em princípio, como benignos, e quando extirpados cirurgicamente, são submetidos a exame anatomopatológico (Leibsoln et al., 1990; Parker, 2012).

\section{1 - Diagnóstico}

O diagnóstico do leiomioma uterino é feito, na maioria dos casos, pela associação de dados da anamnese, dos exames ginecológico e de imagem (Parker, 2012; Keeling \& Reidy, 2007). Deve-se destacar, no diagnóstico diferencial: adenomiose, carcinoma de endométrio e sarcoma uterino. Essas afecções podem ainda coexistir com o leiomioma uterino (Parker, 2007). A confirmação diagnóstica e a definição das características dos nódulos como o posicionamento no útero e sua quantificação, necessitam de exames complementares de imagem (Parker, 2012).

A USTV, devido a sua precisão na identificação dos tumores, facilidade de execução e baixo custo operacional, é o exame mais utilizado (Dueholm et al., 2002(a)). Outros métodos, como a tomografia 
computadorizada, a ressonância magnética da pelve (RM), a histerossonografia e a histerossalpingografia, podem ser usados como complementares à USTV. (Cicinelli et al., 1995; Dueholm et al., 2002(b)).

A RM tem sido utilizada para avaliação das pacientes em que o número de leiomiomas e seu volume são muito grandes dificultando a mensuração de cada um deles por outros métodos de imagem e é considerada como o melhor exame para visualizar o tamanho e a exata localização (Omary et al., 2002).

Indica-se a RM para complementar a USTV, especialmente em úteros maiores que $375 \mathrm{~cm}^{3}$ e úteros com mais de quatro leiomiomas. (Omary et al., 2002; Dueholm et al., 2002(a)). Recomenda-se também nos casos de leiomiomas com dimensões reduzidas, e especialmente em pacientes que serão submetidas ao tratamento conservador, devido a maior acurácia e independência de variação inter-observador (Cura et al., 2006).

No caso dos leiomiomas o contraste entre os tecidos e o comportamento do sinal nas diferentes sequências permite maior precisão diagnóstica (Souza et al., 2003).

\section{2 - Tratamento}

O objetivo do tratamento do leiomioma uterino é o controle dos sintomas e/ou retorno à capacidade reprodutiva, quando assim desejada. 
Dessa forma, a escolha do melhor tipo de tratamento deve ser individualizada (Stewart, 2001).

Apesar de tratar-se de uma doença comum e importante, é notável a falta de estudos que permitam conclusões definitivas sobre os benefícios de um tratamento sobre outro, principalmente a longo prazo, e que possam subsidiar a escolha pelo médico e pela paciente (Viswanathan et al., 2007).

O tratamento clínico, além de controlar e tratar os sintomas, pode evitar ou postergar uma possível intervenção cirúrgica. Avalia-se o quadro clínico, assim como a história clínica da mulher, o desejo reprodutivo e a possibilidade e permissão de submeter-se a cirurgia. Pode ser realizado com o uso de antiinflamatórios não hormonais, antifibrinolíticos e progestagênios ou anticoncepcionais hormonais. Outra opção é o tratamento clínico neoadjuvante, com o emprego dos análogos agonistas do hormônio liberador de gonadotrofinas (GNRH), com a finalidade da redução do volume dos nódulos de leiomioma e a melhora das condições clínicas da paciente para possível procedimento cirúrgico (Bozzini et al., 2003).

O tratamento cirúrgico, por sua vez, pode ser conservador ou radical. O tratamento cirúrgico é a miomectomia realizada através da laparotomia ou ainda por videolaparoscopia ou videohisteroscopia. A terapêutica radical, ou seja, a histerectomia também pode ser efetuada por laparotomia, videolaparoscopia ou ainda por via vaginal (Alelez, 1995; Vercellini et al., 1998) 
Dados do "National Impatient Sample", órgão que tabula dados referentes a internações nos EUA, mostram que em 2007 foram realizadas 264 mil histerectomias por leiomioma uterino, sendo 187 mil abdominais, 30 mil vaginais e 46 mil laparoscópicas. Também foram relizadas 39 mil miomectomias (Gliklich et al., 2011). Naquele país, entre 1997 e 2005, as taxas de histerectomia diminuíram, em média 1,9\% ao ano. E no caso de cirurgias por leiomioma de 31,4\% para 26,9\% (Merrill, 2008). Estes dados podem indicar que cada vez mais mulheres procuram tratamentos menos invasivos (Whiteman et al., 2008). Entre eles, a EAU tem se destacado como método seguro e efetivo. (Volkers et al., 2007; Walker e Bratby, 2007; Kim et al., 2010). Em abril de 1974, Merland realizou a primeira embolização do mioma uterino. Referia-se a uma paciente com menorragia e alto risco cirúrgico. (Ravina et al., 1995; Pinto, 2007).

A utilização como medida profilática para evitar sangramentos intraoperatórios em pacientes portadoras de leiomioma levou Ravina et al. (1995) a indicar a EAU para pacientes que aguardavam a cirurgia, e notaram que a maior parte delas não necessitou de cirurgia depois deste procedimento. Desde então, a técnica foi difundida por vários centros médicos em todo mundo.

No mundo, em 2000, estimava-se mais de dez mil procedimentos realizados (Hovsepian et al., 2009). Em 2007, nos EUA foram realizadas $7363 \mathrm{EAU}$, ou 2,2\% dos tratamentos não-clínicos (Gliklich et al., 2011). Atualmente calcula-se que já foram realizados mais de cem mil procedimentos nos EUA e Europa (Tomislav et al., 2011). 
O objetivo da EAU é levar e depositar, por meio de cateteres e microcateteres, partículas nas artérias uterinas para a oclusão ou redução acentuada do fluxo de sangue para o útero (Katsumori et al., 2002). Com o desenvolvimento deste tratamento surgiram os microcateteres e a utilização de novo material emboligênico, como as esferas calibradas de co-polímero acrílico-Trisacryl e hidrofílicas (Chiesa \& Hart, 2004). Estas são insolúveis em fluídos orgânicos, semi-rígidas quando secas, mas maleáveis quando úmidas, prevenindo deste modo a agregação das partículas no interior do cateter e da circulação, ocluindo os vasos até o nível arteriolar e produzindo um isquemia para o leiomioma, e evitando ou minimizando danos permanentes para o útero (Chua et al., 2005; Bernardo et al., 2011).

São limitações do método: a oclusão unilateral por dificuldade técnica, o espasmo arterial e a dificuldade de ocluir uma eventual anatomose úteroovariana (Kim et al., 2006). Muitas pacientes procuram esta alternativa para preservação da fertilidade, porém apesar das publicações favoráveis à preservação da fertilidade após o procedimento, ainda não há consenso na literatura (Walker \& Bratby, 2007; Tulandi \& Salamah, 2010; Bonduki et al., 2011).

Em comparação com as cirurgias, a EAU tem vantagens como menor permanência no hospital e rápido retorno ao trabalho. A médio e longo prazo, as vantagens são similares nos dois grupos como a melhora da qualidade de vida, porém o número de reintervenção ou tratamento complementar é maior nas pacientes submetidas à EAU (van der Kooji et al., 2011). Com o seguimento, eventualmente, as pacientes necessitam de 
tratamento complementar. Nos casos de EAU foi necessário realizar a histerectomia em 2,9\% em 12 meses (Spies et al., 2005). Em estudo retrospectivo, realizado 5 anos após as EAU, encontrou-se 18,5\% de histerectomias e 5,7\% outros procedimentos como a ablação endometrial, nova EAU ou miomectomia (Gabriel-Cox et al., 2007; van der Kooji et al., 2010)

Portanto, a presença do leiomioma, tumor benigno da musculatura lisa, que acomete o útero em variadas localizações, causando importante impacto na qualidade de vida das mulheres e que tem alta prevalência, sintomatologia e interferência na fertilidade, representa relevante problema de saúde pública. Esses fatos geram grande número de procedimentos cirúrgicos como as histerectomias e miomectomias (Wu et al., 2007). Parte destas mulheres procuram outras alternativas terapêuticas como a EAU. Contudo, após o tratamento cerca de um quinto das pacientes necessitarão de novos procedimentos nos anos subsequentes (van der Kooji et al., 2010). Deste modo, é imprescindível um diagnóstico preciso da doença, em especial quanto ao número e tamanho dos leiomiomas, além de conhecer quais deles terão melhor reposta. Tais fatos motivaram o presente estudo. Assim, procuramos avaliar as ressonância magnética da pelve de pacientes com leiomioma que foram submetidas a embolização da artéria uterina. 


\section{2 - OBJETIVOS}

2.1 - Geral

Avaliar, por meio da ressonância magnética da pelve, em pacientes sintomáticas com leiomioma uterino, a resposta à embolização arterial.

\section{2 - Específico}

Estabelecer os principais parâmetros da ressonância magnética que estão relacionados com a redução volumétrica dos leiomiomas. 


\section{3 - PACIENTES E MÉTODOS}

Realizou-se estudo longitudinal e prospectivo, do diagnóstico por imagem e tratamento do leiomioma uterino sintomático,

As pacientes foram acompanhadas no Setor de Mioma Uterino da Disciplina de Ginecologia do Departamento de Obstetrícia e Ginecologia do Hospital das Clínicas $(\mathrm{HC})$ da Faculdade de Medicina da Universidade de São Paulo (FMUSP). Entre setembro de 2008 e agosto de 2009 foi constituído um grupo de 50 mulheres.

Optou-se por estudar as pacientes atendidas pelo Programa de Apoio ao Desenvolvimento Institucional do Sistema Único de Saúde por meio do protocolo conjunto entre o HC-FMUSP, o Ministério da Saúde e a Sociedade Beneficente Israelita Brasileira Hospital Albert Einstein (HIAE). O número de pacientes foi determinado baseando-se na possibilidade de realizar estes tratamentos em nosso serviço, segundo o Termo de Convênio considerando o disposto no Decreto Federal №. 5.895 de 18 de setembro de 2006 e na Portaria GM/MS no. 3.276, de 28 de dezembro de 2007.

Este estudo foi aprovado pelo Comissão de Ética em Pesquisa do HC-FMUSP (CAPPesq - № 0034/09) e pelo Comitê de Ética em Pesquisa 
do Instituto Israelita de Ensino e Pesquisa Albert Einstein (No 08/926) (Anexo 1).

\section{1 - Caracterização das pacientes}

A idade, cor da pele, antecedentes obstétricos e volume uterino das pacientes estão descritas na Tabela 1. A média etária das pacientes foi 36,3 anos, variando de 27 a 44 anos. Foi considerada a idade em anos completos no momento do tratamento.

A caracterização da cor da pele foi realizada na primeira consulta, sendo que vinte e uma pacientes (42\%) referiram ser brancas. Das 50 pacientes, 18 (36\%) já tiveram gestações. Antes do procedimento a mediana do volume uterino era de $517,7 \mathrm{~cm}^{3}$ (Tabela 1). 
Tabela 1 - Idade, número de gestações, cor da pele e volume uterino das pacientes submetidas a embolização da artéria uterina.

\begin{tabular}{cc}
\hline IDADE - média (Desvio Padrão) & $36,32(3,88)$ \\
GESTAÇÃO & $\mathrm{n}(\%)$ \\
0 & $32(64,0 \%)$ \\
1 & $10(20,0 \%)$ \\
2 & $4(8,0 \%)$ \\
3 & $2(4,0 \%)$ \\
4 & $2(4,0 \%)$ \\
PARIDADE & $\mathrm{n}(\%)$ \\
0 & $34(68,0 \%)$ \\
1 & $11(22,0 \%)$ \\
2 & $4(8,0 \%)$ \\
3 & $1(2,0 \%)$ \\
ETNIA & $\mathrm{n}(\%)$ \\
Branca & $21(42 \%)$ \\
Parda & $13(26 \%)$ \\
Negra & $16(32 \%)$ \\
VOLUME UTERINO (cm $\left.{ }^{3}\right)^{*}$ & $517,7(312,2-648,8)$ \\
\hline *Dados descritos por mediana (intervalo interquartil)
\end{tabular}

\subsection{1 - Critérios de inclusão}

- Diagnóstico ultrassonográfico de leiomioma uterino;

- Presença de sintomas (fluxo menstrual excessivo e/ou dor pélvica crônica) como queixa principal;

- Indicação de EAU (desejo de preservar o útero e contra-indicação à cirurgia);

- Concordância, por escrito, com o termo de consentimento livre e esclarecido (TCLE) (Anexo 2). 


\subsection{2 - Critérios de exclusão}

- Neoplasia genital maligna;

- Moléstia inflamatória pélvica;

- História de alergia ao contraste iodado;

- Apresenta coagulopatia;

- Insuficiência renal;

- História clínica de vasculite;

- Irradiação pélvica (radioterapia);

- Diagnóstico de gestação;

- Leiomioma subseroso cujo pedículo era menor que $50 \%$ do diâmetro do nódulo;

- Indicação de miomectomia;

- Uso de análogo de GNRH.

As pacientes receberam informações sobre o tratamento (assinaram o TCLE) e foram alertadas quanto à possibilidade de realização de histerectomia total abdominal diante da possibilidade de isquemia do útero e endometrite. 
Durante as consultas, 14 mulheres (28\%) discutiram e questionaram, mesmo que hipoteticamente, o desejo reprodutivo e foram orientadas. Nenhuma paciente havia usado GNRH.

\section{2 - Dinâmica do estudo}

Entre setembro de 2008 e agosto de 2009, 610 pacientes foram atendidas e tiveram história clínica, exame físico e exames complementares realizados. Esta rotina obedecia à propedêutica clínica do Setor de Mioma Uterino. Estes procedimentos e orientações às pacientes, levaram a exclusão de 537 pacientes que não tiveram indicação ou não desejavam o procedimento.

As 63 pacientes que aceitaram o tratamento foram orientadas a realizar a RM. 


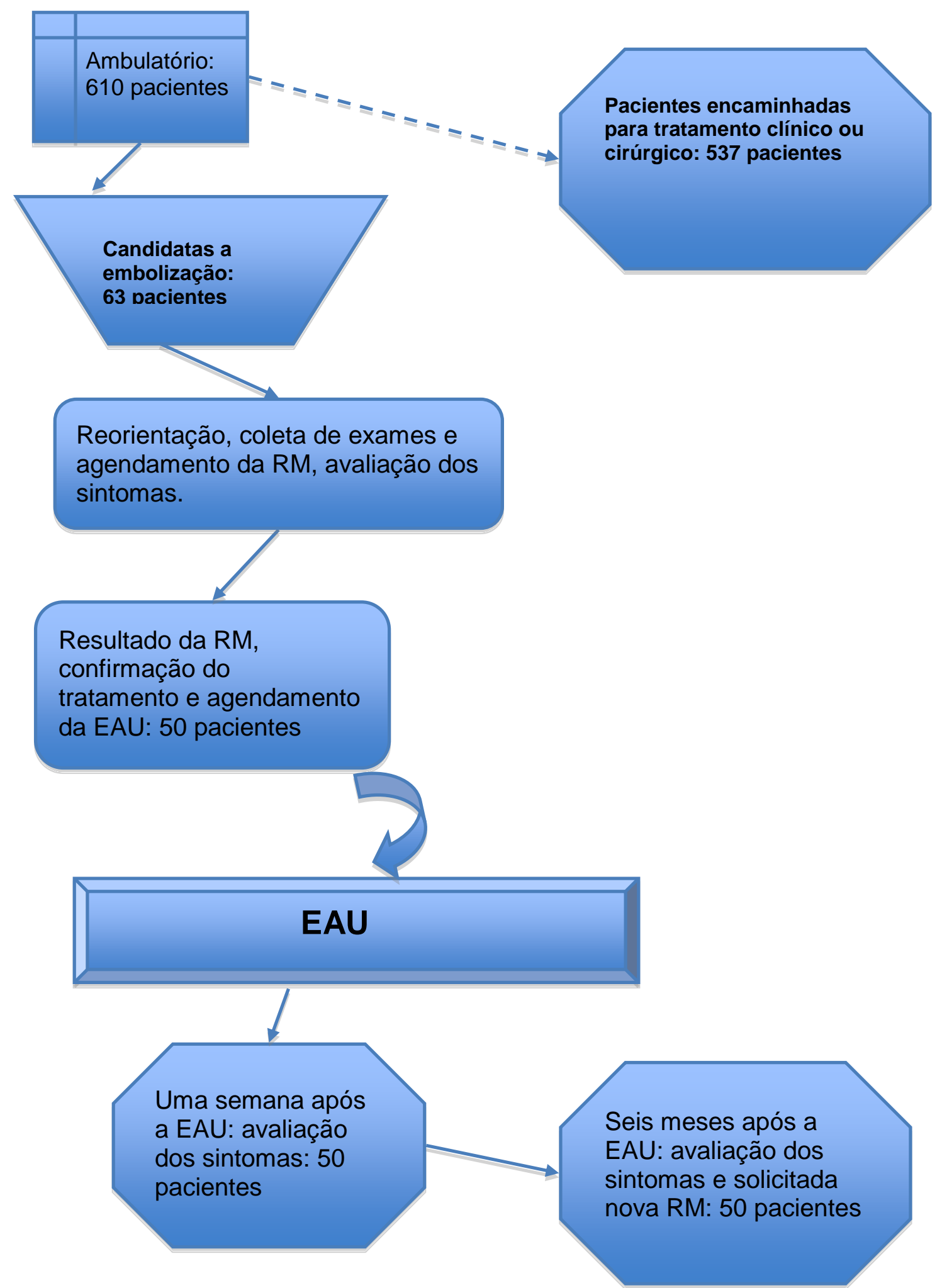

Figura 1 - Dinâmica do estudo, demonstrando as diversas fases do protocolo de atendimento e o número de pacientes 
A dinâmica do estudo como um todo, representada na Figura 1, onde as pacientes seguiram o seguinte fluxo de atendimento:

\section{Consulta 1}

O primeiro contato com o serviço apos a indicação de terapia para os sintomas clínicos, como dor e/ou sangramento. A dor típica era em caráter de cólica de média e forte intensidade que acompanhava os períodos menstruais. Estes se caracterizavam como hipermenorrágicos.

Traziam ultrassonografia do serviço de onde eram referidas e eram orientadas para tratamento adequado, clínico ou cirúrgico. Entre setembro de 2008 e agosto de 2009, foram atendidas 610 pacientes.

Para as pacientes que tinham indicação de tratamento cirúrgico e apresentavam os critérios de inclusão foram apresentadas ao estudo, orientadas sobre o tratamento e quando o aceitavam, assinavam o TCLE. Neste período 63 pacientes assinaram o TCLE.

Realizada a anamnese completa e exames físico geral e ginecológico. Neste momento foi agendada a RM, cerca de 30 dias antes da provável data da EAU, que foram realizadas pelo Setor de Ressonância Magnética do Departamento de Imagem do HIAE.

Os sintomas foram avaliados segundo protocolo do setor, utilizando um escore previamente testado e de uso diário em nossa prática ambulatorial (Hilário et al, 2009) (Anexo 3). 


\section{Consulta 2}

Realizada a avaliação dos exames pré-operatórios, a USTV, a RM e a reorientação das pacientes quanto ao procedimento. Com a confirmação do tratamento era feito o agendamento da EAU.

Foram excluídas nove pacientes que alegaram motivos pessoais, como claustrofobia impossibilitando a RM (três pacientes), adiamento do tratamento por mudança de moradia (duas pacientes) e falta de aprovação familiar (quatro pacientes). Quatro pacientes com história e sintomas típicos de endometriose, com sinais sugestivos na RM foram encaminhadas para tratamento.

\section{Consulta 3}

Uma semana após o procedimento realizou-se a avaliação dos sintomas relacionados ao procedimento como dor, enjôo e febre. Realizado exame físico geral e avaliação do local da punção.

\section{Consulta 4}

Seis meses após o procedimento realizou-se a avaliação dos sintomas e solicitada nova RM.

Sempre que necessário, o pronto-socorro de ginecologia do $\mathrm{HC}$, assim como os médicos da equipe atendiam qualquer intercorrência. 


\section{3 - Ressonância Magnética}

As pacientes foram submetidas a exame de RM em aparelho de alto campo Siemens Magnetom 3-Tesla, disponível no Departamento de Imagem do HIAE. A avaliação por RM foi realizada em duas etapas: a primeira um mês antes do procedimento de embolização das lesões; e a segunda, seis meses após o procedimento. Os exames foram agendados até 15 dias após a menstruação para que todos exames fossem realizados na mesma fase do período menstrual.

Nestas duas etapas foi realizado o protocolo de imagem padrão para avaliação da pelve feminina, acrescida da seqüência ponderadas em difusão, seqüências dinâmicas pós-contraste paramagnético para avaliação do padrão de perfusão das lesões miomatosas.

Os protocolos utilizados na RM foram:

- Axial, Sagital e Coronal T2

- Axial T1, em fase e fora de fase.

- Sagital T2 com saturação de gordura.

- Axial T1 pré e pós administração do contraste.

- Sagital OBL angio-máscara .

- Sagitais OBL angio- dinâmico 5 fases

A interpretação das imagens foi realizada por dois radiologistas especialistas em imagem do abdome e pelve, de maneira independente. Os 
exames pré e pós procedimento foram analisados de forma não seqüencial, aleatória e anônima, visando a minimização de vieses.

$\mathrm{Na}$ RM foram avaliados a morfologia, ou seja, tamanho do(s) leiomioma(s) e do útero em dimensões radiológicas, contorno e medida de volume usando a fórmula para elipse (três eixos ortogonais multiplicado por 0,5233). O número de nódulos de leiomiomas e sua localização no miométrio foram classificados em submucosos, intramurais e subserosos. Foram também avaliados a caracterização do sinal em T2 e a perfusão (Figuras 2, 3 e 4).

O percentual de necrose, quando presente, foi avaliado pelo radiologista de forma binária, maior ou menor que $50 \%$ da área do leiomioma, com intuito de evidenciar possível viés de avaliação da EAU nos casos de leiomiomas que eventualmente já apresentavam necrose e/ou degeneração antes do tratamento.

Em T1 foi realizada a avaliação do padrão de perfusão do contraste (PP), utilizando-se a relação, aqui denominada "Relação PP". São parâmetros desta relação, a fase de maior pico de contraste (FMC) e a fase pré-contraste $(F P C)$ dos nódulos. $A$ relação $P P=\{[F M C$ nódulo $-F P C$ nódulo] / FPC nódulo\} X100 (Sipola et al., 2010).

As demais alterações morfológicas foram observadas nas sequências ponderadas em T2 e avaliou-se imagens onde melhor se visualiza a hidratação dos tecidos. Foram avaliados a intensidade do sinal em T2 do nódulo de leiomioma e do músculo estriado, além da relação chamada 
"Relação T2", ou seja, o valor do sinal do nódulo dividido pelo valor do músculo, ressaltando que o sinal do músculo não se altera com o procedimento. 


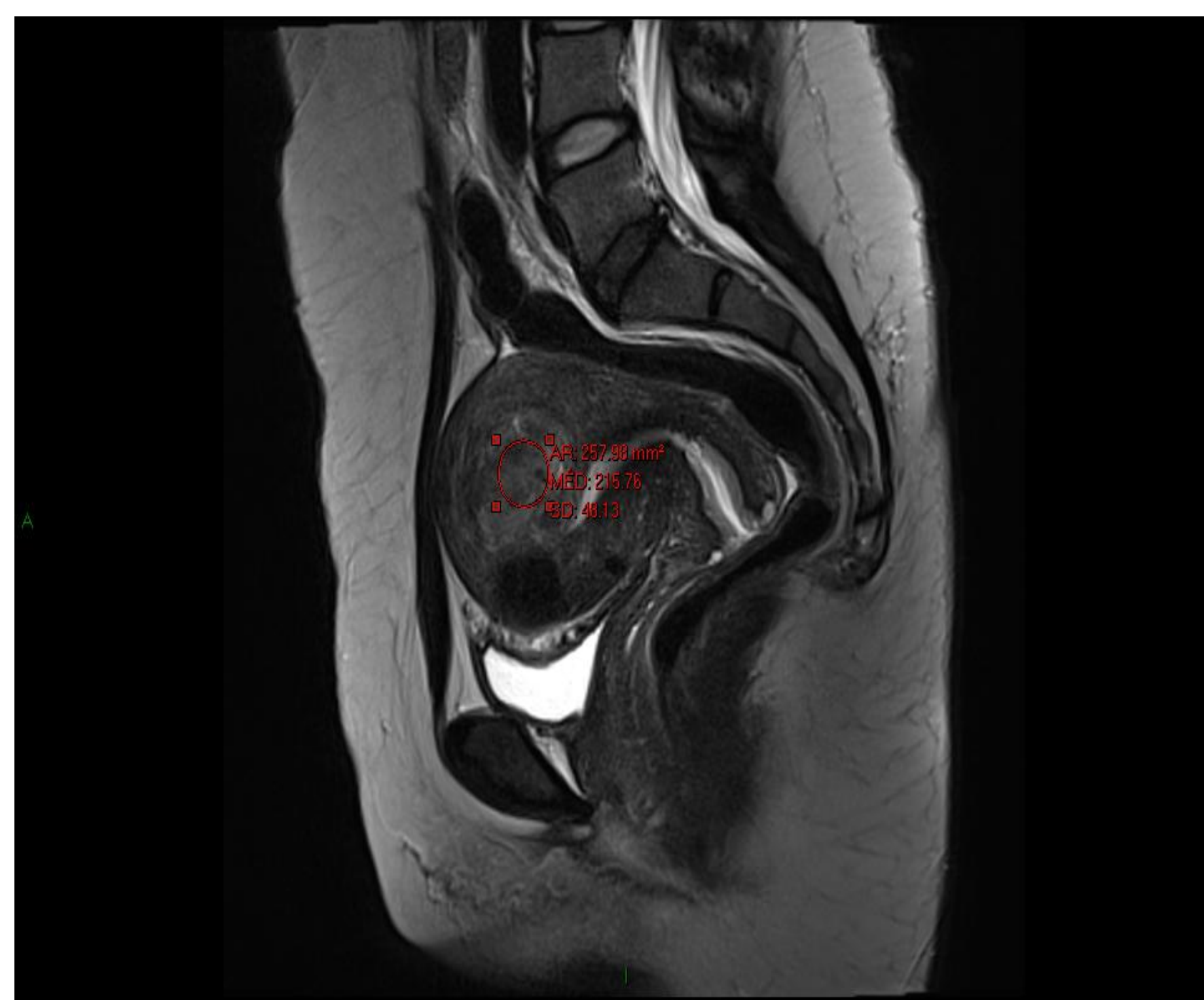

Figura 2 - Ressonância magnética da pelve mostrando a mensuração do sinal em T2 $(215,76 \mathrm{SI})$ em área central de leiomioma intramural. $(\mathrm{SI}=$ medida da intensidade do Sinal) 

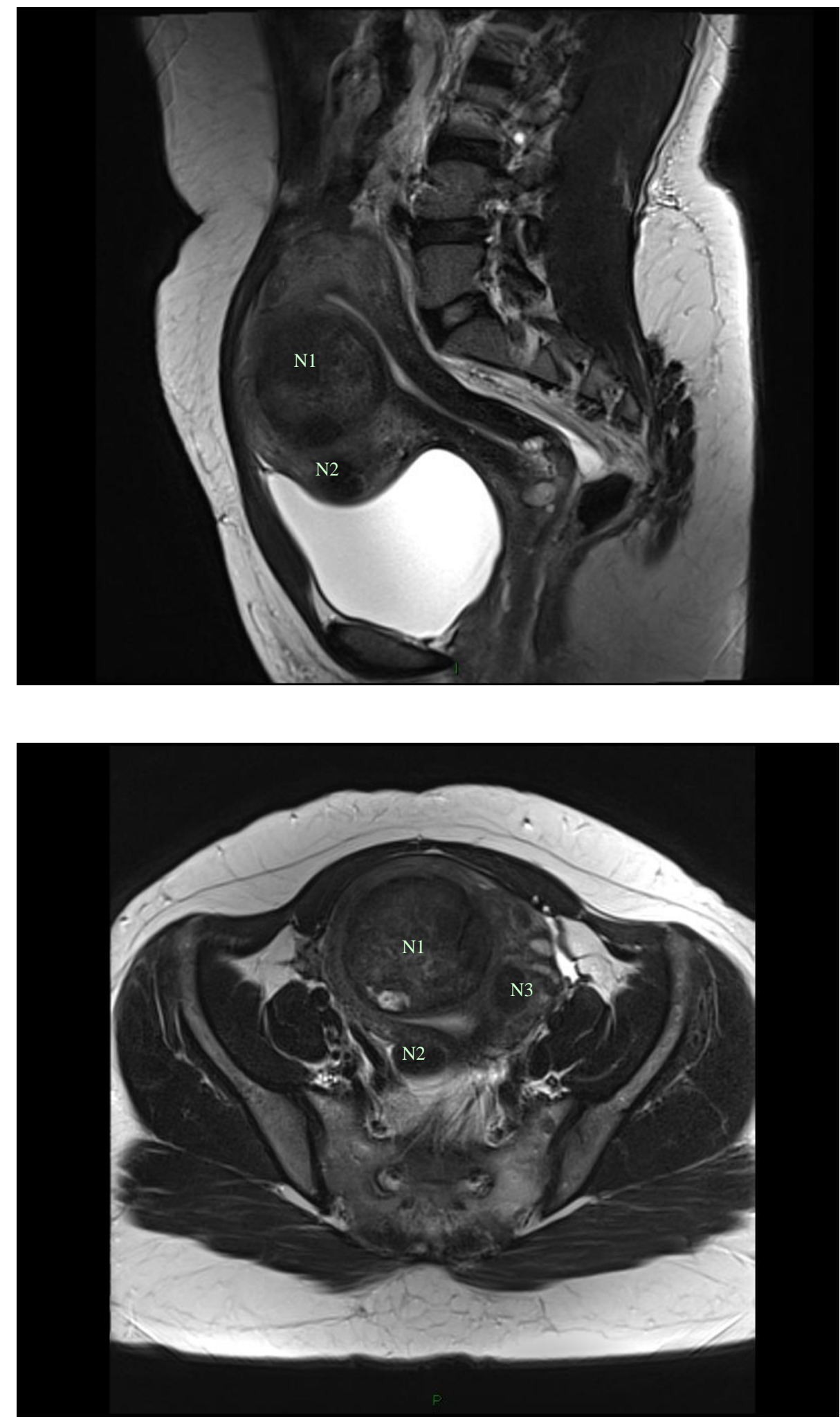

Figura 3 - Diferentes cortes da ressonância magnética da pelve, axial e longitudinal, com 3 nódulos. N1: Localizado na região submucosa anteriormente, com componente intramural. N2: Localizado na parede corporal anterior média, intramural. N3: Localizado na parede corporal antero-inferior direita, intramural. 

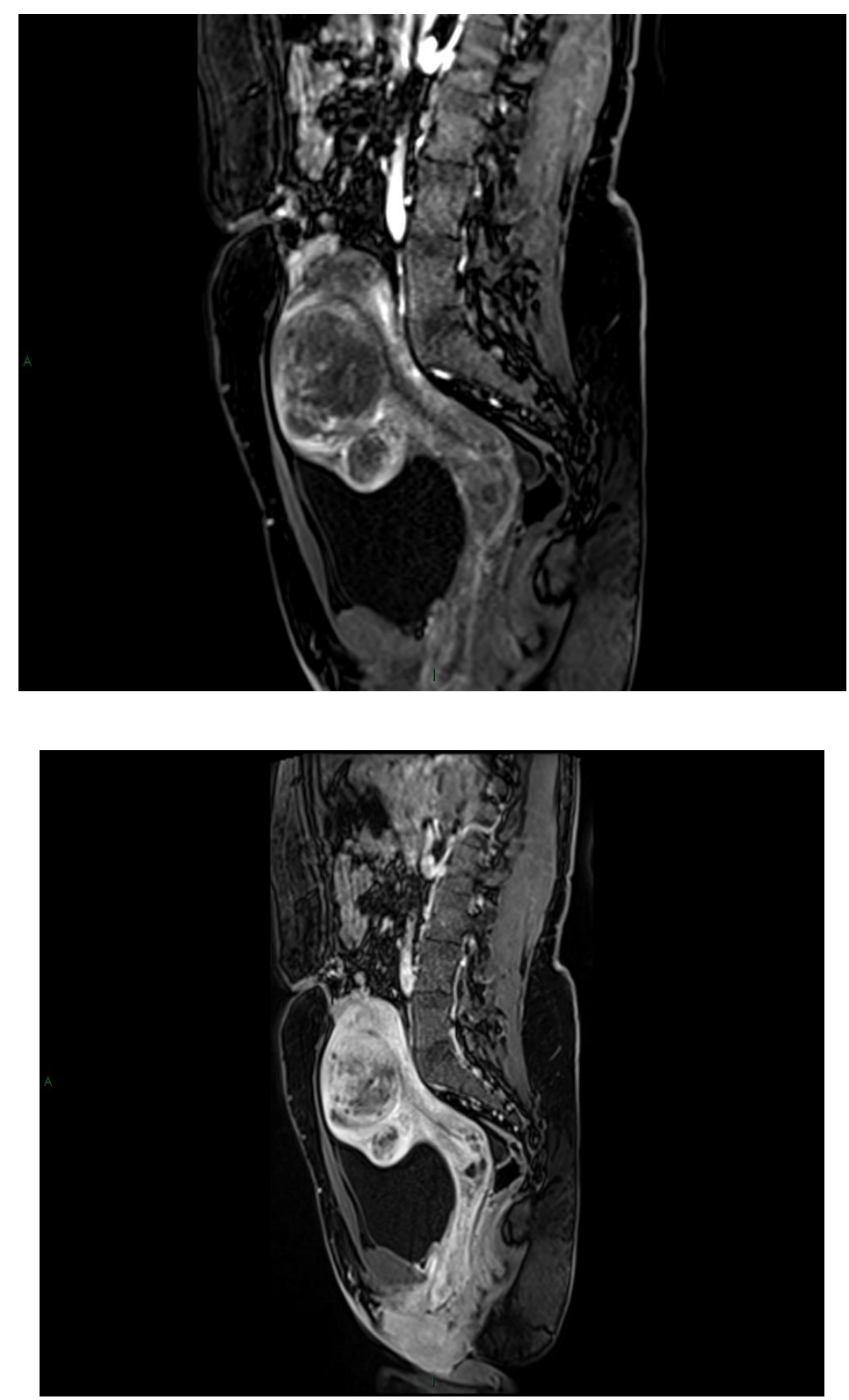

Figura 4 - Ressonância magnética da pelve demonstrando as fases pré e pós contraste. Os leiomiomas apresentam impregnação heterogênea pelo meio de contraste paramagnético, semelhante à observada no miométrio, destacando-se áreas focais de hipocontrastações, compatíveis com necrose/degeneração 


\section{4 - EAU-técnica}

As EAU foram realizadas pelo serviço de Radiologia Vascular Intervencionista (RAVA) do HIAE, sempre por dois médicos contratados e com mais de dez anos de experiência.

A equipe médica do HC foi responsável pela avaliação pré-operatória e o acompanhamento por seis meses, assim como o transporte dos pacientes entre as instituições por ambulância.

As pacientes foram internadas no $\mathrm{HC}$ no dia anterior ao procedimento, reavaliada e permanecia em jejum por 8 horas pré-procedimento.

Eram encaminhadas ao HIAE, por ambulância, onde era realizada a embolização.

A embolização seguiu o protocolo da RAVA:

- $\quad$ Paciente em decúbito dorsal horizontal sob raquianestesia (com morfina);

- $\quad$ Sondagem vesical e antibiótico profilaxia com Cefazolina $1 \mathrm{~g}$ intravenoso;

- $\quad$ Assepsia e antissepsia;

- Punção de artéria femoral comum direita seguindo a técnica de Seldinger;

- $\quad$ Colocação de introdutor valvulado 5 French; 
- Passagem de fio guia hidrofílico, seguido do cateter do tipo Pigtail 5 French;

- Posicionamento do cateter logo acima da bifurcação das artérias ilíacas comuns direita e esquerda;

- $\quad$ Arteriografia pélvica com injeção de $25 \mathrm{ml}$ de contraste com velocidade de injeção de $10 \mathrm{ml} / \mathrm{s}$ e sob pressão de 700 psi;

- $\quad$ Passagem do fio guia para o feixe ilíaco contralateral, seguida da troca do cateter pigtail por um cateter cobra 5 French curva II;

- Realiza-se o cateterismo seletivo da artéria ilíaca interna esquerda;

- Realiza-se a técnica de Roadmap em obliqüidade ipsilateral de 20 a 30 graus, fazendo injeção manual de contraste diluído em soro fisiológico a 0,9\% para visualizar a artéria uterina;

- Utiliza-se uma conexão tipo "Y" heparinizada conectada ao cateter Cobra;

- Introdução de microcateter e microguia para seleção da artéria uterina;

- $\quad$ Conduz-se o microcateter além da emergência do ramo cervical desta artéria;

- Realiza-se uma arteriografia diagnóstica; 
- Injeção de microesferas calibradas de co-polímero acrílico (Embospheres ${ }^{\circledR}$ ) com diâmetro de 500 700 microns, até que o fluxo sanguíneo fique retido no tronco da artéria uterina (5 batimentos por segundo), ou sejam identificados apenas ramos uterinos parietais;

- Realiza -se arteriografia de controle pós-embolização com injeção manual de contraste em seringa de $5 \mathrm{ml}$;

- Retira-se então o microcateter, faz-se a aspiração do cateter cobra com uma seringa vazia para aspiração de possíveis coágulos;

- Realiza-se a manobra de Loop de Waltman com o cateter cobra, seguindo do cateterismo da artéria ilíaca interna ipsilateral a punção;

- Repete-se todos os tempos descritos anteriormente;

- Passagem do fio guia para retirada do cateter Cobra e colocação do Pigtail;

- $\quad$ Posiciona-se o Pigtail ao nível das artérias renais;

- Injeção de contraste arteriografia pélvica de controle com injeção de $30 \mathrm{ml}$ de contraste com velocidade de injeção de 10 $\mathrm{ml} / \mathrm{s}$ e sob pressão de 700 psi;

- $\quad$ Avalia-se na injeção a possível nutrição do(s) nódulos pelas artérias gonadais; 
- $\quad$ Passa-se o fio guia e retirada do pigtail;

- Retirada do introdutor após aspiração do mesmo;

- $\quad$ Compressão manual por 20 min ou utilização de dispositivo hemostático;

- Paciente encaminhada a RPA acompanhado pela equipe de anestesia até o retorno à enfermaria;

- $\quad$ Paciente fica sob analgesia com bomba de PCA (analgesia contínua ou patient continous anestesia).

Quanto a anestesia, realizada pela equipe de anestesia do HIAE, seguiu-se o seguinte protocolo:

- Administra-se uma hora antes da cirurgia por via oral $20 \mathrm{mg}$ de oxicodona de liberação lenta para os pacientes e a cada 12 horas, por 24 horas;

- Realiza-se raquianestesia com bupivacaína pesada $15 \mathrm{mg}$ e morfina 200 mcg e sedação com propofol;

- $\quad$ No final do procedimento cetoprofeno $100 \mathrm{mg}$ e dipirona $2 \mathrm{~g}$;

- Para profilaxia de náuseas, vômitos e prurido durante e após 0 procedimento:

Ondansetrona $8 \mathrm{mg}$ a cada 8 horas,

> Dexametasona $5 \mathrm{mg}$ (só no intra-operatório), 
$>\quad$ Difenidramina $50 \mathrm{mg}$ se prurido a cada 6 horas.

- $\quad$ Para resgates de analgesia realiza-se administração de bolus de morfina $2 \mathrm{mg}$ com o PCA, com intervalo de cinco minutos e limite de $20 \mathrm{ml}$ em 4 horas;

- A intensidade da dor deve ser avaliada no pós-operatório por meio da escala verbal analógica de 0 a 10.

As pacientes ficaram três horas em observação na recuperação pósanestésica do setor, sob supervisão do anestesista e da equipe de radiologia intervencionista, até serem liberadas, e voltarem com ambulância para o HC. Conforme acordo prévio, entre as equipes de anestesia do HIAE e do HC, as pacientes permaneciam por 24 horas com controle contínuo de analgesia pelo paciente (PCA) possibilitando melhor analgesia. Com o PCA, o paciente controla a dose de analgesia, até o limite estipulado pelo anestesista, conforme o protocolo descrito.

A EAU requer, normalmente uma noite no hospital, para observação da estabilidade hemodinâmica e analgesia. Quando tinham alta, 24 horas após o procedimento, eram orientadas ao retorno para consulta, ou antes quando necessário, e levavam prescrição de analgésico e antiinflamatório não hormonal (Dipirona e Cetoprofeno) e antieméticos (Ondasetron). 


\section{5 - Método Estatístico}

As variáveis quantitativas foram descritas em médias, desvios padrão e intervalos de confiança ou em medianas e intervalos interquartis nos casos de distribuição não normal. As variáveis qualitativas foram descritas em freqüências absolutas e porcentagens.

As comparações entre pré e pós embolização em relação ao volume do útero, valores do músculo em T2 foram analisadas pelo teste de Wilcoxon.

O resultado do procedimento foi avaliado com base na redução percentual no volume dos nódulos. Para identificar os efeitos de diversos fatores sobre a redução percentual do volume dos nódulos, foram realizadas análises univariadas e multivariadas. Foram adotados modelos de equações de estimação generalizadas, considerando a resposta binária, ou seja, a redução, ou não, maior que $50 \%$ do volume. Estes modelos foram utilizados com o intuito de contemplar a dependência entre as medidas realizadas em diferentes nódulos de uma mesma paciente. Em ambas as abordagens, as variáveis que apresentaram $p<0,20$ na análise univariada foram incluídas nos modelos multivariados.

Para identificar um ponto de corte em relação à variável "Relação T2" que discriminasse pacientes com redução maior que $50 \%$ no volume dos nódulos foi realizada a análise de Curva ROC (Receiver Operator Characteristics Curve). Para avaliar o desempenho dos resultados obtidos 
através da curva ROC, foi apresentado o valores da área sob a curva (AUC). Um valor abaixo de 0,5 indica que a curva tem baixo poder de discriminação. Quanto maior o valor da área melhor o poder de discriminação.

O nível de significância adotado foi 0,05 . Todas as análises foram realizadas utilizando o programa estatístico SPSS (versão 17.0; SPSS, Inc, Chicago, III). 


\section{4 - RESULTADOS}

\section{1 - Análise das medidas antes e após a embolização por paciente (útero).}

A redução percentual do volume do útero nas 50 pacientes variou de 0,67\% a 93,53\%, com média de 38,91\%, IC95\% $(33,41 ; 44,41)$. Os valores de volume do útero após a embolização diminuíram conforme apresentado na tabela $2(p<0,001)$ (Tabela 2$).$

Tabela 2 - Comparação, pela ressonância magnética, entre os volumes uterino antes e após a embolização da artéria uterina

\begin{tabular}{lcccccc}
\hline & \multicolumn{2}{c}{ Antes da embolização } & \multicolumn{3}{c}{ Após-embolização } \\
& Mediana (IIQ) & Mínimo & Máximo & $\begin{array}{c}\text { Mediana } \\
\text { (IIQ) }\end{array}$ & Mínimo & Máximo \\
\hline Volume & & & & 256,5 & & \\
do & $517,7(312,2-648,8)$ & 118,0 & 2136,0 & $(184,0-$ & 64,0 & 1634,0 \\
nódulo & & & & $464,0)$ & & \\
$\left(\mathrm{cm}^{3}\right)$ & & & & & \\
\hline
\end{tabular}

Dados descritos em mediana (IIQ =intervalo interquartil); valor $p$ referente à comparação entre antes e após a embolização $p<0,001$

4.2 - Análise das medidas antes e após embolização dos nódulos de leiomioma 


\subsection{1 - Caracterização dos nódulos de leiomioma}

Neste estudo foram avaliados 179 nódulos de leiomiomas de 50 pacientes. O número mediano de nódulos por paciente foi 3 , variando de 1 a 8. A Tabela 3 contém a descrição dos nódulos estudados, a maioria era intramural e com volume acima de $10 \mathrm{~cm}^{3}$.

Tabela 3 - Caracterização, pela ressonância magnética, dos nódulos de leiomioma, segundo a localização no miométrio e pelo seu volume dividido em tercis

\begin{tabular}{lc}
\hline & $\mathrm{n}(\%)$ \\
\hline Localização do nódulo no miométrio & \\
$\quad$ Intramural & $133(74,3 \%)$ \\
Subseroso & $34(19,0 \%)$ \\
$\quad$ Submucoso & $12(6,7 \%)$ \\
Volume dos nódulos pré embolização* & \\
$\quad$ Até 10 & $59(33,0 \%)$ \\
$>10$ e <=56 & $60(33,5 \%)$ \\
$>56$ & $60(33,5 \%)$ \\
\hline
\end{tabular}

${ }^{*}$ Volume em $\mathrm{cm}^{3}$

Dos 130 nódulos sem diagnóstico de necrose, na RM, antes da embolização, 124 passaram a apresentar necrose após o procedimento, entre os quais a maioria (116 nódulos - 93,5\%) tinha necrose maior que $50 \%$. Onze nódulos possuíam necrose menor que 50\% antes da embolização. Destes, 9 (81\%) passaram a apresentar necrose maior que 
$50 \%$ depois da embolização. Após a embolização, 160 nódulos $(89,4 \%)$ apresentavam necrose maior que 50\% (Tabela 4).

Tabela 4 - Descrição da presença de necrose nos nódulos comparando os momentos antes e após a embolização da artéria uterina

\begin{tabular}{lccccc}
\hline & & \multicolumn{3}{c}{ Presença de necrose - após } & \multirow{2}{*}{ Total } \\
\cline { 3 - 5 } & & Não & Sim $\leq 50 \%$ & Sim $>50 \%$ & \\
\hline Presença de & Não & $6(4,6 \%)$ & $8(6,2 \%)$ & $116(89,2 \%)$ & 130 \\
\multirow{2}{*}{ necrose - antes } & Sim $\leq 50 \%$ & $0(0,0 \%)$ & $2(18,2 \%)$ & $9(81,8 \%)$ & 11 \\
& Sim $>50 \%$ & $0(0,0 \%)$ & $3(7,9 \%)$ & $35(92,1 \%)$ & 38 \\
\hline
\end{tabular}

As porcentagens estão descritas em relação à presença de necrose antes

\subsection{2 - Medidas dos nódulos de leiomioma}

A maioria dos nódulos observados apresentou redução de volume após a embolização (Tabela 5), assim como diminuição na intensidade do sinal em T2.

Tabela 5 - Medidas do volume dos nódulos e valor do sinal em T2 antes e após a embolização da artéria uterina

\begin{tabular}{|c|c|c|c|c|c|c|}
\hline & \multicolumn{3}{|c|}{ Antes da embolização } & \multicolumn{3}{|c|}{ Após-embolização } \\
\hline & $\begin{array}{l}\text { Mediana } \\
\text { (IIQ) }\end{array}$ & Mínimo & Máximo & Mediana (IIQ) & Mínimo & Máximo \\
\hline $\begin{array}{l}\text { Volume do } \\
\text { nódulo } \\
\left(\mathrm{cm}^{3}\right)\end{array}$ & $\begin{array}{l}21,50 \\
(7,40- \\
81,60)\end{array}$ & 0,5 & 703 & $\begin{array}{c}7,00(1,00- \\
35,00)\end{array}$ & 0 & 449,5 \\
\hline $\begin{array}{l}\text { Valor do } \\
\text { sinal } \\
\text { nódulo T2 } \\
\text { (SI) }\end{array}$ & $\begin{array}{c}87,00 \\
(63,00- \\
142,00)\end{array}$ & 18 & 390 & $\begin{array}{c}50,00(34,00- \\
82,00)\end{array}$ & 23 & 388 \\
\hline
\end{tabular}




\subsection{3 - Análise da redução percentual do volume dos nódulos}

A redução percentual do volume dos nódulos variou de $-40,63 \%$ a $100,00 \%$, com média de 55,23\% e desvio padrão 31,80\% (Figura 5).

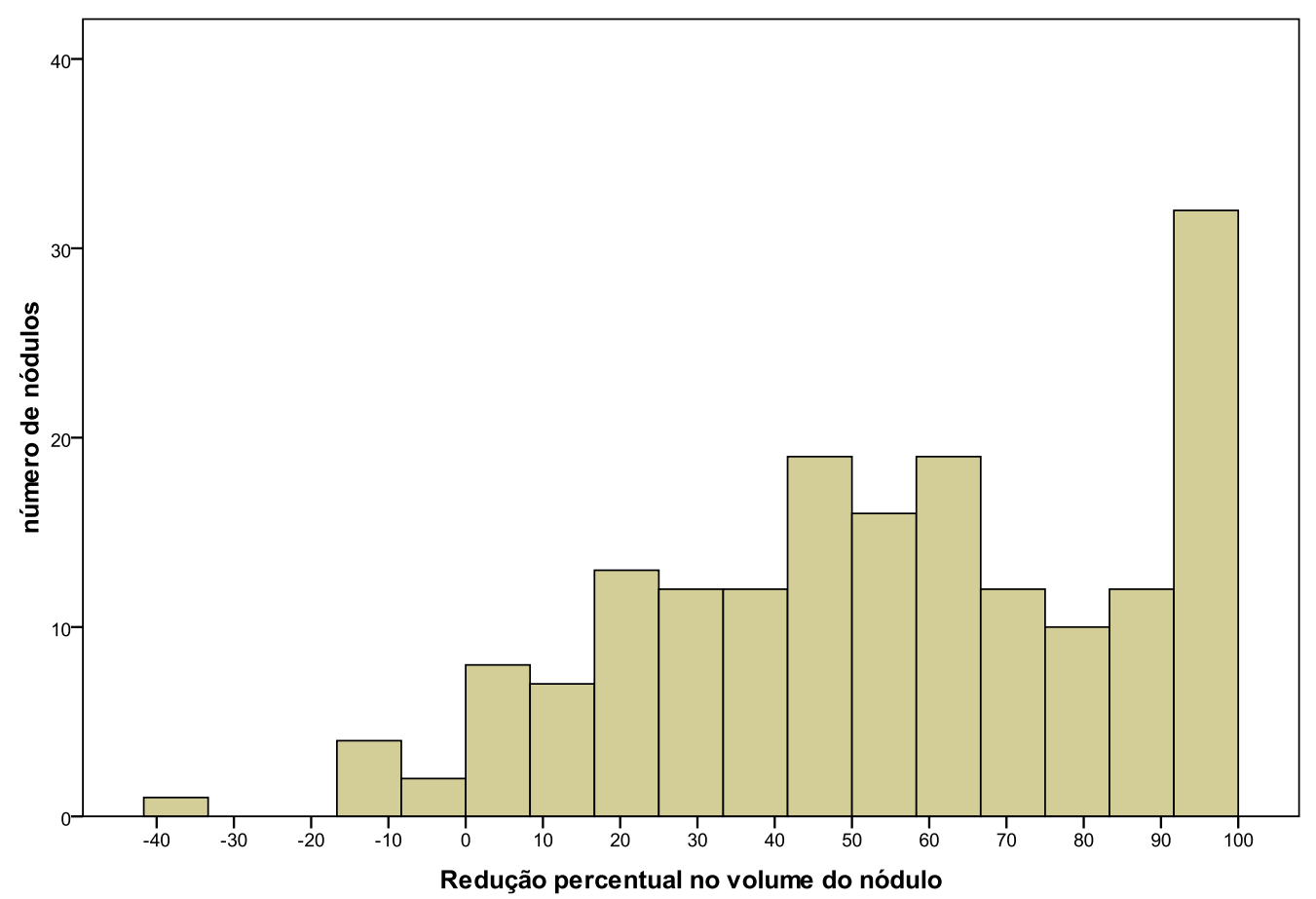

Figura 5 - Redução percentual do volume dos nódulos (-40 a 100\%)

Quando a localização dos nódulos no miométrio era submucosa, observouse maior redução no volume destes (Figura 6). 


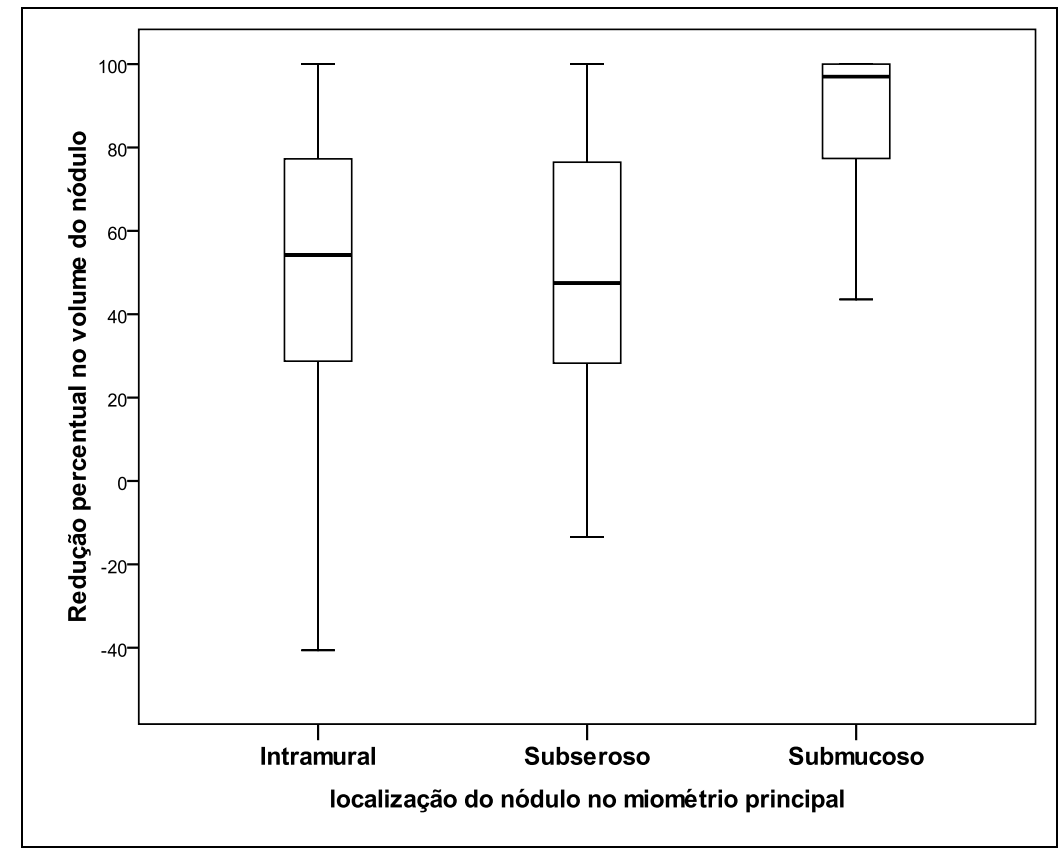

Figura 6 - Medidas de redução percentual do volume dos nódulos nas diferentes localizações no miométrio

A redução nos nódulos submucosos foi maior em relação às outras localizações no útero e mostrou-se significativa em relação aos subserosos $(p=0.010)$.

As Figuras 7 e 8 ilustram a redução percentual do volume dos nódulos para diferentes volumes antes da embolização (categorizados segundo os tercis da distribuição) e quanto a quantidade de nódulos. 


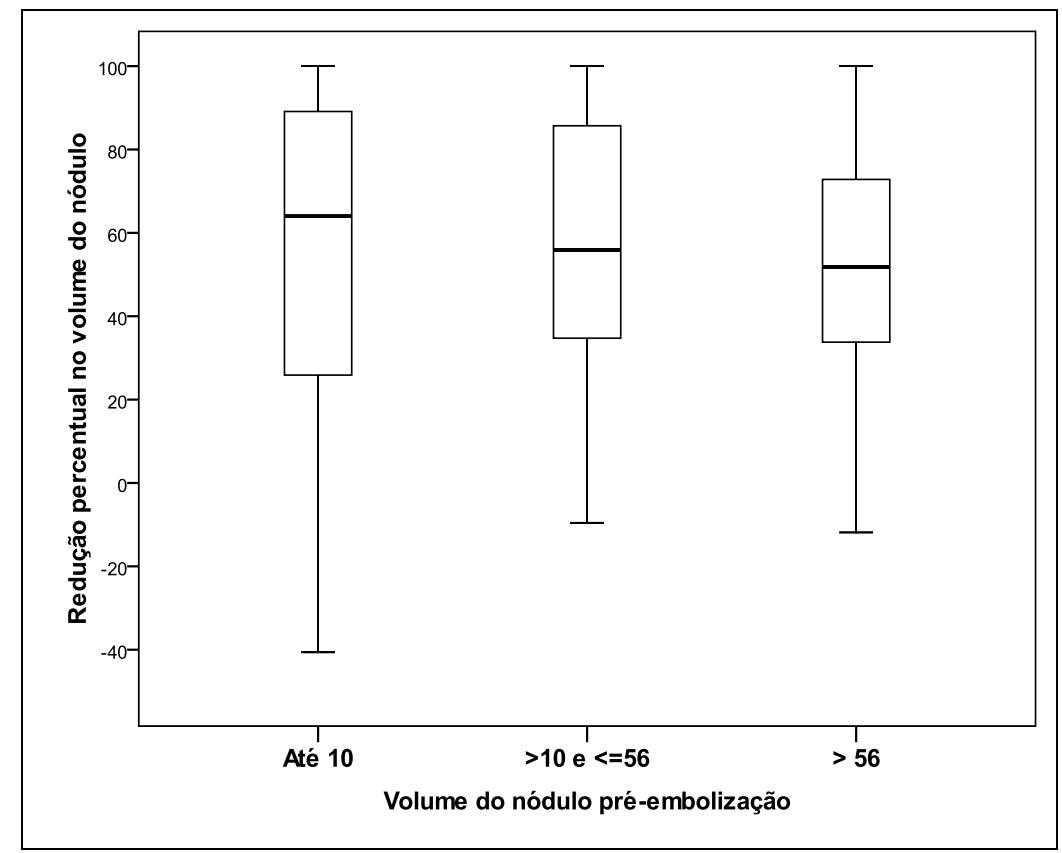

Figura 7 - Redução percentual do volume dos nódulos de acordo com seu tamanho $\left(\mathrm{cm}^{3}\right)$ antes do tratamento

Ao comparar a redução dos maiores leiomiomas, que tinham volume maior que $56 \mathrm{~cm}^{3}$, não houve diferença significativa em relação aos menores de $10 \mathrm{~cm}^{3}(p=0,631)$ ou dos intermediários, com volume entre 10 e $56 \mathrm{~cm}^{3}$ $(p=0,394)$. 


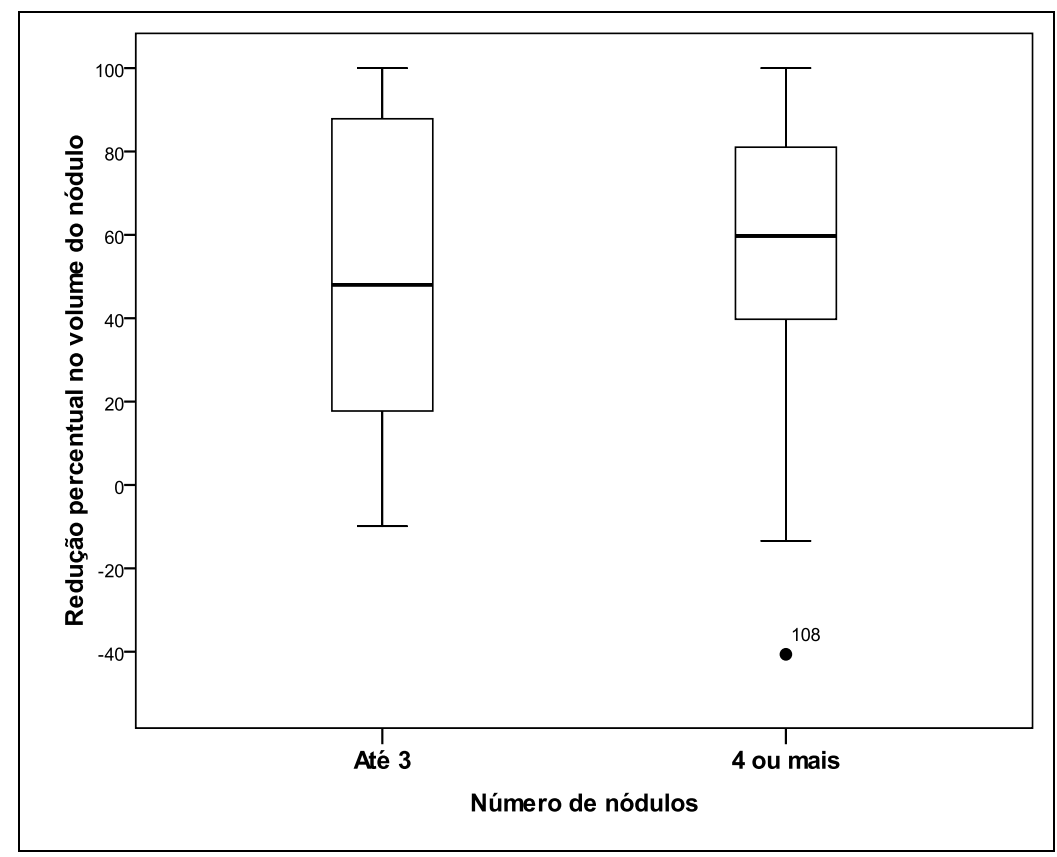

Figura 8 - Redução percentual do volume de acordo com o número de nódulos em cada útero

Comparando-se a redução dos leiomiomas, em útero com até três nódulos com os que tinham quatro ou mais nódulos, não houve diferença significativa $(p=0,258)$.

Para identificar os fatores que influenciaram a redução percentual do volume dos nódulos foi considerada como variável dependente a redução percentual maior que 50\% (variável binária). Para avaliação conjunta das diversas variáveis, realizou-se análise multivariada com as que apresentaram $\mathrm{P}<0,20$ na análise univariada. Nesta análise, considerando a variável dependente binária, as variáveis localização do nódulo no miométrio, sinal do nódulo em T2 e relações PP e Relação T2 foram 
selecionadas para o modelo multivariado, em que a relação PP e o sinal do nódulo em T2 deixaram de ser significantes (Tabela 6).

O ajuste do modelo multivariado mostrou que quanto maior o valor da Relação T2, maior a chance de redução maior que $50 \%$ no volume dos nódulos (OR: 1,528; 95\% IC: 1,186-2,149, $\mathrm{p}=0$ 0,015).

Em relação à localização do nódulo no miométrio, observou-se que a chance de redução maior que $50 \%$ no volume do nódulo é maior quando a localização do nódulo é submucosa quando comparado ao subseroso (OR: 0,056; IC: 0,006-0,504, $p=0,010)$. Os volumes do útero e do nódulo antes da embolização foram características que não apresentaram associação com maior redução percentual do volume dos nódulos. 
TABELA 6 - Resultados da análise univariada e multivariada - variável dependente: redução maior que $50 \%$

\begin{tabular}{|c|c|c|c|c|c|c|}
\hline & \multicolumn{3}{|c|}{ Univariada } & \multicolumn{3}{|c|}{ Multivariada } \\
\hline & OR & IC (95\%) & $\mathrm{P}$ & OR & $\mathrm{IC}(95 \%)$ & $p$ \\
\hline $\begin{array}{l}\text { Volume do útero } \\
\text { pré-embolização }\end{array}$ & 1,000 & $(0,999 ; 1,001)$ & 0,725 & & & \\
\hline $\begin{array}{l}\text { Localização do } \\
\text { nódulo no miométrio } \\
\text { Intramural / } \\
\text { Submucoso }\end{array}$ & 0,099 & $(0,010 ; 0,952)$ & 0,045 & 0,132 & $\begin{array}{c}(0,016 \\
1,095)\end{array}$ & 0,061 \\
\hline $\begin{array}{l}\text { Subseroso / } \\
\text { Submucoso }\end{array}$ & 0,051 & $(0,005 ; 0,526)$ & 0,012 & 0,056 & $\begin{array}{c}(0,006 \\
0,504)\end{array}$ & $0,010^{*}$ \\
\hline $\begin{array}{l}\text { Volume do nódulo } \\
\text { (tercis) } \\
\text { Até } 10 \text { / maior que } \\
56 \\
\text { Entre } 10 \text { e } 56 \text { / maior } \\
\text { que } 56\end{array}$ & $\begin{array}{l}1,206 \\
1,386\end{array}$ & $\begin{array}{l}(0,561 ; 2,594) \\
(0,654 ; 2,937)\end{array}$ & $\begin{array}{l}0,631 \\
0,394\end{array}$ & & & \\
\hline $\begin{array}{l}\text { Relação nódulo / } \\
\text { músculo T2 } \\
\text { (Relação T2) }\end{array}$ & 1,262 & $(1,063 ; 1,500)$ & 0,008 & 1,528 & $\begin{array}{l}(1,086 \\
2,149)\end{array}$ & $0,015^{*}$ \\
\hline Relação PP & 1,005 & $(0,998 ; 1,012)$ & 0,167 & 1,005 & $\begin{array}{l}(0,998 \\
1,013)\end{array}$ & 0,174 \\
\hline $\begin{array}{l}\text { Valor do sinal nódulo } \\
\text { T2 }\end{array}$ & 1,004 & $(0,999 ; 1,009)$ & 0,080 & 0,997 & $\begin{array}{l}(0,988 \\
1,006)\end{array}$ & 0,463 \\
\hline $\begin{array}{l}\text { Número de nódulos } \\
\text { menor que } 4 \text { / maior } \\
\text { ou igual a } 4\end{array}$ & 0,637 & $(0,292 ; 1,391)$ & 0,258 & & & \\
\hline
\end{tabular}

$$
{ }^{*} p<0,05
$$

\section{3 - Comparações entre as variáveis PP e Relação T2 nos nódulos consoante suas localizações no miométrio}

Os nódulos de leiomioma, quando submucosos foram preditores de melhor resposta a EAU. Para uma melhor análise destes nódulos e para 
conhecer a influência da composição do tecido e vascularização medida pela RM, comparou-se as variáveis PP e Relação T2 com as demais localizações no útero.

Tabela 7 - Relação T2 (nódulo/músculo em T2) nos leiomiomas nas diferentes localizações no miométrio

\begin{tabular}{llccc}
\hline & & \multicolumn{3}{c}{ Localização do nódulo no miométrio } \\
& Média (DP) & Intramural & Subseroso & Submucoso \\
\hline \multirow{4}{*}{ Relação T2 } & $2,39(2,17)$ & $3,06(2,39)$ & $1,92(0,53)$ \\
& Mínimo & 0,41 & 0,79 & 1,00 \\
& Máximo & 14,96 & 8,62 & 2,74 \\
& $N$ & 133 & 34 & 11 \\
\hline
\end{tabular}

DP - desvio padrão

Conforme a tabela 7, não houve diferença estatisticamente significante entre os nódulos nas diferentes localizações $(p=0,146)$.

Tabela 8 - Relação PP nos leiomiomas nas diferentes localizações no miométrio

\begin{tabular}{llccc}
\hline & & \multicolumn{3}{c}{ Localização do nódulo no miométrio } \\
& & Intramural & Subseroso & Submucoso \\
\hline \multirow{3}{*}{ Relação PP (DP) } & $40,65(45,04)$ & $38,43(31,40)$ & $77,12(43,01)$ \\
& Ménimo & $-38,38$ & $-26,70$ & 10,49 \\
& Máximo & 227,21 & 94,13 & 145,12 \\
& $N$ & 132 & 34 & 11 \\
\hline
\end{tabular}

DP - desvio padrão 
Conforme os valores da tabela 8 , houve diferença estatisticamente significante entre as localizações $(p=0,022)$. Nas comparações entre as localizações duas a duas, nota-se que há diferença entre os submucosos e intramurais $(p=0,004)$ e entre submucosos e subserosos $(p=0,008)$. Entre intramurais e subserosos não houve diferença estatisticamente significante $(p=0,982)$.

\section{4 - Curva ROC para determinar ponto de corte}

Na curva ROC, para a variável "Relação T2", o ponto que maximiza a soma de sensibilidade e especificidade é o ponto 2,00 , com sensibilidade $53,0 \%$ e especificidade $73,1 \%$ (AUC = 0,644) (Figura 9). 


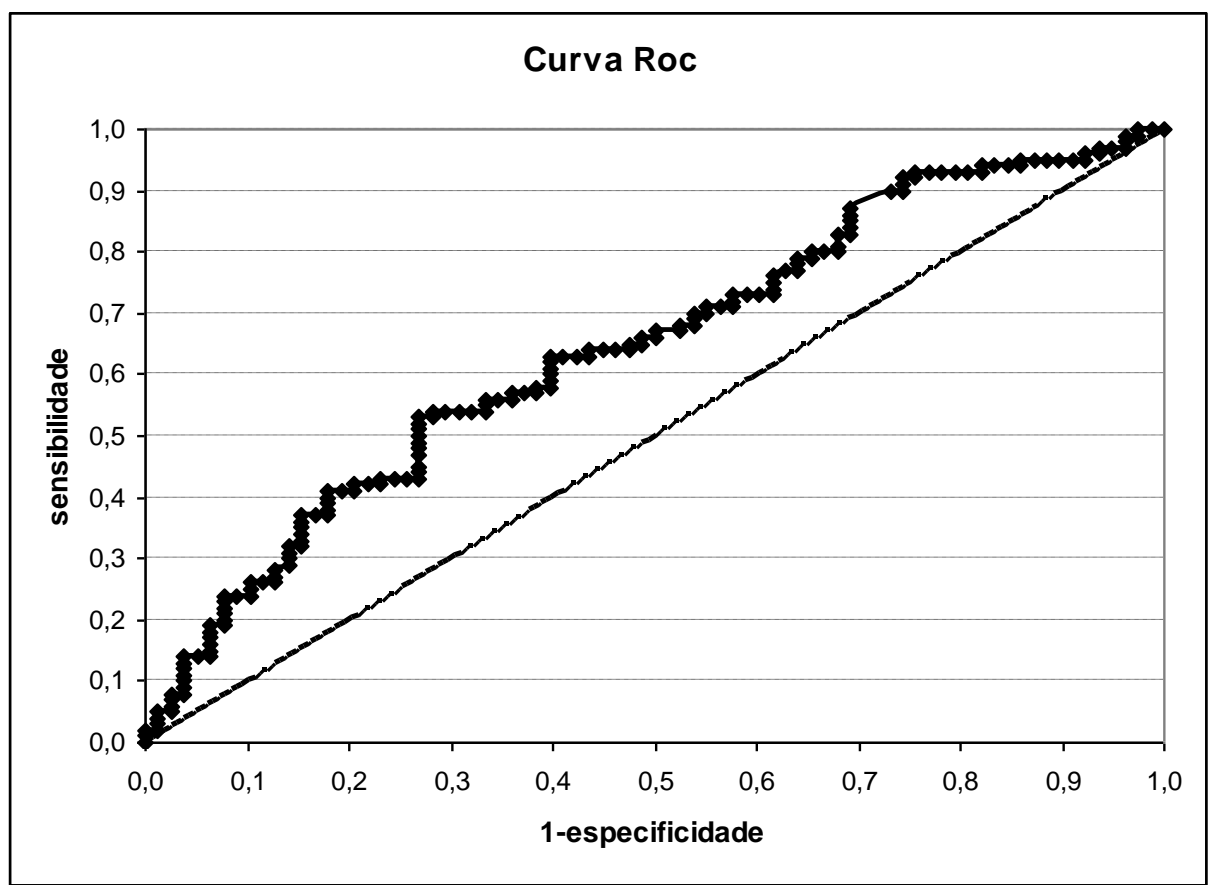

Figura 9 - Curva ROC analisando a sensibilidade e especificidade da Relação T2

Não foi possível estabelecer pontos de corte adequados para esta variável, pois a área sobre a curva $\mathrm{ROC}$ apresentou valores baixos para a variável, e nenhum valor analisado produziu sensibilidade e especificidade satisfatória para definir um ponto de corte. 


\section{5 - DISCUSSÃO}

\section{1 - O estudo}

A embolização uterina é técnica consagrada, segura e eficaz (GabrielCox et al., 2007; Bradley, 2009; Van der Kooji, et al., 2010).

O número de pacientes submetidos à EAU no Brasil ainda é restrito, pois não é um tratamento financiado pelo Sistema Único de Saúde (SUS). Ainda trata-se de procedimento de custo pouco estudado no sistema de saúde brasileiro, porém é reconhecido pelo Ministério da Saúde como alternativa para o tratamento de miomatose (Portal do Ministério da Saúde, 2010 e da Agência nacional de Saúde Suplementar). Nosso estudo reforça essa tendência e traz desafios para o conhecimento médico, na medida em que o entendimento do método pelos especialistas está aumentando, mas pelos pacientes ainda é pouco difundido.

\section{2 - A Ressonância Magnética}

A pouca disponibilidade da RM nos serviços públicos pode justificar a falta de pesquisas deste recurso diagnóstico relacionadas com o leiomioma em nosso meio. Com a perspectiva de liberação da EAU no âmbito do SUS e do sistema suplementar, torna-se importante estabelecer protocolos que 
justifiquem a utilização da RM, evitando aumento injustificado da demanda e possivelmente a selecionando de maneira eficiente a indicação de pacientes.

Para avaliação dos úteros e leiomiomas utilizamos a RM 3-Tesla, disponível no serviço do HIAE para pesquisas. Apesar do custo mais elevado, a RM demonstra maior capacidade em medir e localizar leiomiomas uterinos que o USTV (Dueholm et al., 2002 (a); Keeling e Reidy, 2007). Há comprovação da maior reprodutibilidade da RM em relação ao USTV, histerossonografia e histeroscopia, diminuindo, nesse caso, a dependência do examinador na eficácia do exame (Projeto Diretrizes- AMB, 2010).

$\mathrm{Na}$ comparação entre RM e ultrassonografia de 49 pacientes sintomáticos, a diferença encontrada entre o número de nódulos, localização e o volume uterino, alterou a conduta em $11(22,4 \%)$ pacientes (Spielmann et al., 2006). No estudo de Kim et al. (2010), a RM foi importante para controle de complicações, pois encontraram com facilidade, a localização de tecidos necróticos que ao serem removidos, resolveram sintomas dolorosos ou secreção vaginal cronicamente aumentada. Nikolaidis et al. (2005) mudaram a conduta de 22 em 100 pacientes que iriam ser submetidas à EAU, após a RM, com base em achados como tamanho do leiomioma, presença de adenomiose isolada, e as lesões do endométrio.

Em outro estudo, $18 \%$ dos casos indicados para EAU mudaram de procedimento após a RM por encontrarem outro diagnóstico (Cura et al., 2006). No presente estudo quatro (8\%) pacientes tiveram suas condutas alteradas após a RM. 
Estes estudos destacam a necessidade do diagnóstico correto e preciso na indicação terapêutica, buscando o melhor interesse da paciente. Também fortalecem a utilização da RM nos casos onde a EAU é uma opção (Spielman et al., 2006).

Assim, ainda que a restrição de acesso deva ser considerada, e sua necessidade questionada em pacientes com uma avaliação satisfatória pela USTV, o ginecologista deve utilizar este método diagnóstico sempre que ficar em dúvida quanto à indicação do tratamento.

\section{3 - Leiomiomas}

Estudaram-se todos os nódulos de leiomioma do grupo de pacientes. Poucos autores estudaram todos os nódulos (Burn et al., 2000; Jha et al., 2000), e em número inferior ao deste estudo. Outros autores, como Sipola et al. (2010) optaram por estudar apenas o maior nódulo ou o nódulo dominante de cada paciente. O estudo do nódulo dominante deve ser discutido a luz do pouco conhecimento da inter-relação vascular entre os diversos nódulos, e da diferença de comportamento pela grande variação genética A mudança do tamanho e vascularização de um nódulo afeta os nódulos vizinhos assim como o miométrio adjavente (Rein et al., 1991; Walocha et al., 2003).

Estudou-se a diminuição volumétrica dos 179 leiomiomas das 50 pacientes, acompanhando-as por seis meses, baseados em estudos que 
mostraram que neste período a redução dos leiomiomas ocorreram com maior intensidade e os sintomas haviam melhorado na maioria dos casos (Harman et al., 2006; Van der Kooji et al., 2010; Jha et al., 2000).

A presença de necrose maior que $50 \%$ na maioria dos nódulos indica a eficiência do método, quanto a desvascularização, o que pode traduzir-se em melhora clínica. Katsumori et al. (2002) encontrou menor taxa de recidiva dos sintomas, assim como menor chance de novos procedimentos quando a área de necrose foi maior que $90 \%$. No presente estudo a maioria dos nódulos ficaram com área de necrose maior que 50\%, porém, não foi possível correlacionar com dados de sucesso clínico.

No presente estudo, assim como nos estudos de Gabriel-Cox et al. (2007) e de Sipola et al (2010) a idade do paciente não apresentou correlação com a redução de tamanho. No estudo de Jha et al. (2000) o aumento da idade foi um preditor negativo de sucesso. É importante ressaltar a dificuldade de comparação quando a média etária dos pacientes, que nas pacientes do presente estudo foi 36,3 anos, enquanto que nos estudos anteriormente citados foi 45, 48 e 45 anos, respectivamente. Estes dados tornam-se mais importantes ao se comparar resultados em longo prazo de estudos cujas pacientes estão próximas a menopausa, quando é maior a probabilidade de resolução dos sintomas (Tropeano et al., 2010).

A mediana do volume dos úteros $\left(517,7 \mathrm{~cm}^{3}\right)$ foi semelhante aos descritos por Gabriel-Cox et al. (2007) em estudo multicêntrico. Não obtivemos neste trabalho diferença no percentual de redução volumétrica nos diferentes volumes uterinos, resultados iguais aos encontrados por 
Gabriel-Cox et al. (2007) e Prollius et al. (2004). Bernardo et al. (2011) estudaram mulheres com útero de volume médio semelhante $\left(538 \mathrm{~cm}^{3}\right)$, mas naquele estudo quanto maior o volume inicial maior foi a redução percentual.

Neste estudo encontrou-se taxa de sucesso de clínico de 100\%, e expulsão transcervical de $2 \%$, o que está de acordo como o Protocolo de Qualidade da Sociedade Européia de Radiologia Intervencionista (Hovsepian et al., 2009) que sugere limite de $96 \%$ e $5 \%$, respectivamente. Outros pesquisadores como Bradley (2009) encontraram sucesso clínico de $94 \%$ e levantamento de Gupta et al. (2006) em estudo feito junto a Cochrane Database, encontrou melhora mínima de $85 \%$.

No presente estudo não houve trombose venosa profunda, necrose uterina ou embolização acidental de outros alvos. O período pós procedimento ocorreu de forma habitual e foram utilizados medicamentos sintomáticos como antiinflamatórios não hormonais, analgésicos e antieméticos (Messina et al., 2002). Foram seis pacientes atendidas por urgências, sendo quatro casos de dor, e uma ficou internada por 24 horas. Um caso de dispnéia com suspeita de tromboembolismo pulmonar, foi internado para diagnóstico e observação e descartado. E um caso de sangramento por mioma parido. Neste último caso, mesmo após o tratamento inicial, o sangramento persistiu e foi realizada miomectomia.

A diminuição dos leiomiomas foi de $55,23 \%$ e do útero $38,91 \%$, ante a expectativa na literatura de 60 e 40\%. (Burn et al., 2000; Hovsepian et al., 2009; Bradley, 2009). 
Em nosso estudo não houve associação entre o tamanho do leiomioma e sua redução volumétrica. Assim, em termos de redução de tamanho, as pacientes com leiomiomas grandes são boas candidatas para a EAU bem como pacientes com leiomiomas menores. Outros autores encontraram resultado semelhante quanto ao tamanho do leiomiomas (Spies et al., 2002; Sipola et al., 2010).

Encontrou-se neste estudo, maior diminuição do volume do leiomioma quando estes eram submucosos. Jha et al. (2000) descreveram a preditividade na maior redução volumétrica quando a localização no miométrio foi submucosa. No estudo de Spies et al. (2002), leiomiomas de localização submucosa foram associados a maiores reduções do volume, após a EAU, em comparação com leiomiomas subserosos. Essa diferença, porém, não persistiu em 12 meses. Em outro estudo (Sipola et al., 2010), a localização do leiomioma não teve efeito significativo na redução de tamanho do leiomioma, porém, nesta casuística notava-se apenas 2 nódulos submucosos de um total de 47. Estes estudos avaliaram apenas os nódulos dominantes, o que pode interferir na sua comparação e análise, pois sua localização muda o perfil vascular e genético (Rein et al., 1991; Walocha et al., 2003).

É importante ressaltar que as variáveis acima citadas, como a idade, a localização do leiomioma e utilização de nódulo dominante, podem dificultar a comparação entre os estudos. Encontrou-se distribuição heterogênea e dados discrepantes, o que pode ser esperado em estudos de pacientes com miomatose com grande volume uterino médio e do número 
de nódulos. O número de nódulos por paciente variou de 1 a 8 , o que dificultou estimar uma matriz de correlação e as relações apresentam coeficientes de assimetria elevados.

Em grupos assim distribuídos, a variação nos sintomas e a resposta terapêutica justificam novas pesquisas onde se individualiza a localização dos nódulos. O estudo das alternativas terapêuticas do tratamento conservador do leiomioma uterino, assim como do diagnóstico e indicação, passa por um maior conhecimento destes parâmetros.

\section{4 - Parâmetros radiológicos: valor em T2, relação T2 e relação PP}

Supõe-se que a EAU possa causar maior redução de tamanho em leiomiomas não degenerados, com maior vascularização, os quais se apresentam com alto sinal em T2 à RM. No presente estudo, houve tendência a maior redução do tamanho do leiomioma em nódulos com alto sinal em T2, entretanto não obtivemos significância estatística ao analisar esta variável $(p=0,08)$, o que está em conformidade com os achados de Burn et al. (2000); Harman et al. (2006); Sipola et al. (2010). Contudo, Yamashita et al. (1993) descreveram que leiomiomas degenerados apresentaram maior sinal em T2 e maior redução volumétrica. Assim, mais estudos são necessários e é possível que existam outros fatores que não a degeneração e celularidade ou talvez a superposição destes aspectos, que eventualmente expliquem a variabilidade destes resultados. 
A intensidade do sinal do leiomioma em T2 pode ter diferenças causadas pelo biotipo do paciente, e ao se comparar nódulos que possuem interdependência de uma mesma paciente, com nódulos de outras pacientes, tornou-se necessário utilizar um denominador comum de cada paciente. Assim, a relação nódulo/músculo em T2 permitiu ajustar estas diferenças, e mostrou-se significante após a análise multivariada. A mesma relação foi utilizada nos estudos de Sipola et al. (2010) e de Jung et al. (2012) para avaliação prévia de pacientes submetidas à EAU.

Esta técnica de análise de imagens mostrou-se viável, e manteve-se estatisticamente significante após análise multivariada, o que não ocorreu com a análise direta do sinal do leiomioma em T2.

Toda a análise da imagem pode ser feito com software que possa medir na área de interesse nos tecidos a SI, consequentemente este tipo de medida é viável para o trabalho clínico de rotina, com a integração do radiologista, ginecologista e radiologista intervencionista (Parker, 2012).

O valor da Relação PP em nosso estudo foi controverso. Na análise multivariada não estava associada com a redução do volume de leiomioma. Esta resposta é corroborada pelos resultados de Burn et al. (2000) e De Souza e Williams (2002). Porém, ao avaliarmos os nódulos submucosos como preditores de redução volumétrica, a relação PP nestes, foi estatisticamente significante quando comparados com os leiomiomas intramurais e subserosos, o que sugere maior vascularização nestes nódulos. Possivelmente o comportamento dos nódulos segue um padrão 
diferente, segundo a vascularização destes e do miométrio ao redor, o que ainda não é totalmente conhecido (De Souza e Williams, 2002).

Os nódulos submucosos quando comparados aos demais, não apresentaram diferença significante na relação T2. Esta relação pode denotar leiomiomas com diferentes distribuições de sua celularidade e tecido conjuntivo, cuja distribuição entre os leiomiomas nas demais localizações foi igual.

$\mathrm{Na}$ análise das variáveis que podem relacionar-se com a diminuição volumétrica dos leiomiomas, não se encontrou relação com volume do útero, volume do leiomioma, número de nódulos, intensidade do sinal em T2.

Na pesquisa de Sipola et al. (2010), também não encontraram relação entre a diminuição volumétrica e o volume do leiomioma antes da embolização. Eles descreveram a relação PP e encontraram relação com a diminuição dos leiomiomas; e aqui avaliada, não apresentou diferença no resultado da terapia. Assim, como o presente estudo, Sipola et al., encontraram maior redução quando encontraram maiores valores da Relação T2, mas naquele estudo, não foi significante. 


\section{5 - Pontos de corte}

Os resultados deste estudo podem dar ao ginecologista por meio de integração com o radiologista, ferramentas para melhor avaliação da RM, instrumentalizando sua decisão quanto a conduta, posto que o ajuste dos modelos mostrou que quanto maior o valor da relação nódulo/músculo em T2, maior foi chance de redução maior que $50 \%$ no volume dos nódulos.

Seria mais prático a adoção de um ponto de corte, a partir do qual poder-se-ia esperar maior chance de redução acima de 50\%. Buscando facilitar a interpretação dos resultados, construiu-se uma curva ROC com o objetivo de obter um ponto de corte capaz de discriminar adequadamente os nódulos que apresentaram redução maior que $50 \%$ no volume e os que apresentaram redução menor ou igual a 50\%. Não foi possível estabelecer pontos de corte adequados para esta variável, pois a área sobre a curva ROC apresentou valores baixos para as duas variáveis, e nenhum valor analisado produziu sensibilidade e especificidade satisfatória para definir um ponto de corte. É possível que estudos com um número maior de nódulos possam produzir este parâmetro.

\section{6 - Relação da diminuição volumétrica com melhora clínica}

No presente estudo a principal variável de desfecho foi a redução volumétrica do leiomioma. 
As pacientes tiveram melhora clínica, independente da maior redução volumétrica. Assim, deve-se valorizar a história clínica, tendo cuidado especial em pacientes com úteros e/ou leiomiomas volumosos e com maior chance de nova abordagem, por nova embolização ou por miomectomia.

A melhora clínica relacionada com a maior diminuição volumétrica ainda é discutida. Segundo De Souza e Williams (2002), a redução de volume do leiomioma não necessariamente se correlaciona com melhora dos sintomas clínicos, mas a redução do tamanho da área submucosa pode ser mais importante na sintomatologia que o tamanho do leiomioma. Outros autores demonstraram que a menor redução de tamanho esteve associada com piores desfechos clínicos, tais como falha clínica e histerectomia (Goodwin et al., 1999) ou recorrência dos sintomas (Pelage et al., 2004). A redução volumétrica do leiomioma é uma meta importante do tratamento e influencia a evolução do paciente.

Novos estudos com maior tempo de seguimento também são necessários para avaliar se as medidas encontradas na RM podem ser utilizadas para predizer redução do tamanho do leiomioma e do útero e a resposta clínica como alívio dos sintomas.

\section{7 - Reintervenção}

Acompanhando as pacientes por dois anos, diversos autores encontraram que cerca de $12 \%$ das pacientes necessitaram de 
histerectomias (Kim et al., 2010; Volkers et al., 2007; Sipola et al., 2010), chegando a $27 \%$ em cinco anos (Van der Kooji et al., 2010). Comparando com outras terapias, encontra-se, após miomectomia, taxa de recorrência de 12,7\% em dois anos (Stewart et al., 2002; Spies et al., 2005 (b)) e 16,7\% em cinco anos (Doridot et al., 2001) e de $27 \%$ em dez anos (Candiani et al., 1991).

Com a mudança na abordagem para o tratamento menos invasivo de leiomiomas uterinos por embolização das artérias uterinas, e o acesso a RM por parte da população, a utilização de parâmetros da RM, pelo ginecologista, é importante para planejamento da terapia. Se a paciente apresentar leiomiomas submucosos, valores altos da relação T2 pode-se discutir a terapia com maior segurança, pois são fatores preditivos de maior redução volumétrica. Novos estudos podem ser realizados para confirmar os achados, e no futuro sugerir valores, a partir dos quais o ginecologista e sua paciente podem ter a tranqüilidade de ter, um ótimo resultado terapêutico.

Assim, quando orientamos e informamos a paciente sobre métodos alternativos e conservadores do tratamento do leiomioma uterino, é importante ressaltar que parte delas necessitará de novas intervenções. Para avaliação dessas intervenções sugere-se buscar entender quais os leiomiomas podem ter melhor resposta. 


\section{6 - CONCLUSÃO}

Houve, à ressonância magnética, redução volumétrica dos leiomiomas uterinos de pacientes submetidas a embolização da artéria uterina.

Os parâmetros da ressonância magnética relacionados com a maior redução volumétrica dos leiomiomas uterinos foram a localização submucosa e a maior relação nódulo/músculo em T2. 


\section{7 - ANEXOS}

\section{Anexo - 1 - Aprovação}

\section{APROVAÇĀO}

A Comissão de Ética para Análise de Projetos de Pesquisa CAppesa da Diretoria Clínica do Hospital das Clínicas e da Faculdade de Medicina da Universidade de São Paulo, em sessão de 17/06/2009, AProvOU O Protocolo de Pesquisa $n^{\circ}$ 0034/09, intitulado: "USO DA RESSONÂNCIA NUCLEAR MAGNÉTICA 3-T DA PELVE COMO FATOR PREDITIVO DE SUCESSO CLÍNICO, EM PACIENTES SUBMETIDAS À EMBOLIZAÇÃO DO MIOMA UTERINO" apresentado pelo Departamento de OBSTETRÍCIA E GINECOLOGIA, inclusive o Termo de Consentimento Livre e Esclarecido.

Cabe ao pesquisador elaborar e apresentar à CAPPesa. os relatórios parciais è final sobre a pesquisa (Resoluçāo do Conselho Nacional de Saúde $n^{\circ}$ 196, de 10/10/1996, inciso IX.2, letra "C"I.

Pesquisador (a) Responsável: Dr. Marcos de Lorenzo Messina

Pesquisador (a) Executante: Eduardo Zlotnik

CAPPesq, 29 de Junho de 2009

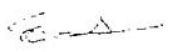

Prof. Dr. Eduardo Massad Presidente da Comissão de Ética para Análise de Projetos de Pesquisa

Comissăo de Ética para Análise de Projetos de Pesquisa do HCFMUSP e da FMUSP Diretoria Clínica do Hospital das Clínicas da Faculdade de Medicina da Universidade de São Paulo Rua Ovidio Pires de Campos, 225. 5 andar 01130696442 Fax: 01130696492 e-mait cappesq@hcnet.usp.br/ secretariacappesq2@hcnet.usp.br 
Anexo 1 - Aprovação

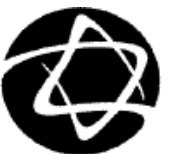

ALBERT EINSTEIN

ENSTINTO ISRAELITA DEA

São Paulo, 25 de agosto de 2008

Ref. CEP/Einstein No 08/926

CAAE - 0167.0.028.000-08

Título: Uso da Ressonância magnética 3-T como fator preditivo de sucesso clínico, em pacientes submetidas ao tratamento por embolização do mioma uterino..

Investigador Principal: Dr. Eduardo Zlotnik

Ilmo. Sr.

Dr. Eduardo Zlotnik

O Comitê de Ética em Pesquisa do Hospital Israelita Albert Einstein analisou e aprovou o projeto de pesquisa supracitado, bem como o Termo de Consentimento Livre e Esclarecido, do projeto de pesquisa supracitado.

Aproveitamos a oportunidade para orientar o pesquisador sobre os seguintes itens:

- O sujeito da pesquisa tem a liberdade de recusar-se a participar ou de retirar seu consentimento em qualquer fase da pesquisa, sem penalização alguma e sem prejuízo ao seu cuidado (Res. CNS 196/96 - Item IV.1.f) e deve receber uma cópia do Termo de Consentimento Livre Esclarecido, na íntegra, por ele assinado (Item IV.2d).

- O Pesquisador deve desenvolver a pesquisa conforme delineada no protocolo aprovado e descontinuar o estudo somente após análise das razões da descontinuidade pelo CEP que o aprovou (Res.CNS 196 Item III. 3z), aguardando seu parecer, exceto quando perceber risco ou dano não previsto

ao sujeito participante ou quando constatar a superioridade de regime oferecido a um dos grupos da pesquisa (Item V.3) que requeiram ação imediata. 
- O CEP deve ser informado de todos os efeitos adversos ou fatos relevantes que alterem o curso normal do estudo (Res. CNS Item V.4). É papel do pesquisador assegurar medidas imediatas adequadas frente a evento adverso grave ocorrido

(mesmo que tenha sido em outro centro) e enviar notificação ao CEP e à Agência Nacional de Vigilância Sanitária - ANVISA - junto com seu posicionamento.

- Eventuais modificações ou emendas ao protocolo devem ser apresentadas ao CEP de forma clara e sucinta, identificando a parte do protocolo a ser modificada e suas justificativas. Em caso de projetos do Grupo I ou II apresentados anteriormente à ANVISA, o pesquisador ou patrocinador deve enviá-las também à mesma, junto com o parecer aprovatório do CEP, para serem juntadas ao protocolo inicial (Res. 251/97. item III.2.e).

- Relatórios parciais e finais devem ser apresentados ao CEP, inicialmente em Fevereiro de 2009.

Atenciosamente,

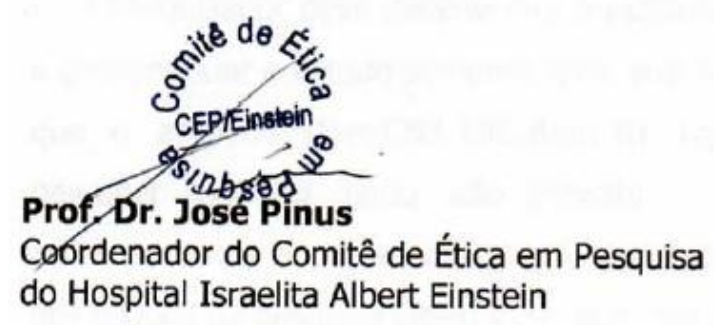


Anexo - 2 - Consentimento Livre e Esclarecido

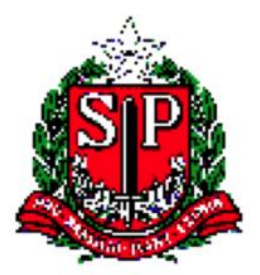

HOSPITAL DAS CLÍNICAS

DA

FACULDADE DE MEDICINA DA UNIVERSIDADE DE SÃO PAULO

HOSPITAL DAS CLÍNICAS DA FACULDADE DE MEDICINA DA UNIVERSIDADE DE

SÃO PAULO-HCFMUSP

TERMO DE CONSENTIMENTO LIVRE E ESCLARECIDO

DADOS DE IDENTIFICAÇÃO DO SUJEITO DA PESQUISA OU RESPONSÁVEL LEGAL

1. NOME:

DOCUMENTO DE IDENTIDADE № : SEXO: $M \square F \square$

DATA NASCIMENTO: .......................

ENDEREÇO

CIDADE

№

APTO:

BAIRRO:

TELEFONE: DDD

2.RESPONSÁVEL LEGAL

NATUREZA (grau de parentesco, tutor, curador etc.) $z$.

DOCUMENTO DE IDENTIDADE :

DATA NASCIMENTO.: ....................

ENDEREÇO:

BAIRRO:

CIDADE:

...SEXO: $M \square F \square$

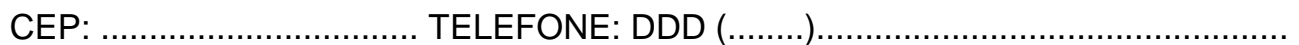

\section{DADOS SOBRE A PESQUISA}

1. TÍTULO DO PROTOCOLO DE PESQUISA: Uso da ressonância nuclear magnética da pelve como fator preditivo de sucesso clínico, em pacientes submetidas à embolização do mioma uterino.

2. PESQUISADOR : Prof. Dr. Marcos de Lorenzo Messina

CARGO/FUNÇÃO: Médico voluntário do Departamento de Obstetrícia e

Ginecologia

INSCRIÇÃO CONSELHO REGIONAL № 85.014

PESQUISADOR : Dr. Eduardo Zlotnik

CARGO/FUNÇÃO: Médico do Hospital Israelita Albert Einstein (SBIBAE)

INSCRIÇÃO CONSELHO REGIONAL № 73.681

3. AVALIAÇÃO DO RISCO DA PESQUISA:

RISCO MÍNIMO $\square$ RISCO BAIXO X RISCO MÉDIO $\square \quad$ RISCO MAIOR

4.DURAÇÃO DA PESQUISA : 18 meses

1 - Desenho do estudo e objetivo(s) "essas informações estão sendo fornecidas para sua participação voluntária neste estudo, que visa......."; ou "o objetivo deste estudo é.....";

Você foi selecionada para fazer parte de um estudo que tem como objetivo avaliar as características radiológicas, por meio da angio-ressonância nuclear magnética 3-T como fatores preditivos de sucesso de embolização arterial uterina, em portadoras de miomatose uterina sintomáticas.

Sua participação não é obrigatória e a qualquer momento, você poderá desistir de participar e retirar seu consentimento. Sua recusa não trará nenhum prejuizo no tratamento, bem como em sua relação com o médico pesquisador ou com a Instituição. 
As informações obtidas através dessa pesquisa serão confidenciais e asseguramos o sigilo sobre sua participação. Os dados não serão divulgados de forma a possibilitar sua identificação.

2 - Descrição dos procedimentos que serão realizados, com seus propósitos e identificação dos que forem experimentais e não rotineiros;

Não se aplica

3 - Relação dos procedimentos rotineiros e como são realizados - coleta de sangue por punção periférica da veia do antebraço; exames radiológicos;

Em parceria com o Hospital das Clínicas da Faculdade de Medicina da Universidade de São Paulo (HC-FMUSP), a avaliação pré oporatória será realizada nesta Instituição (HCFMUSP), bem como o acompanhamento quer se dará até seis meses após o procedimento. Caso necessário, a Senhora continuará em acompanhamento.

A Ressonância nuclear magnética (RM) será realizada no H. Israelita Albert Einstein. O aparelho de ressonância magnética tem o formato de um túnel no qual você entra deitado, e algumas pessoas não se sentem bem dentro dele. Se isto acontecer, poderá nos avisar através de um microfone instalado dentro do aparelho, ou apertando um botão, e será prontamente atendido. O ruído (barulho) do aparelho é alto, mas haverá um protetor de ouvido para diminuir o seu desconforto. Não existe radiação que possa prejudicá-lo. A Sra. precisará ficar imóvel durante o tempo de exame e ouvirá o som do aparelho de ressonância magnética.

O procedimento de embolização de artéria uterina será realizado no $\mathrm{H}$. Israelita Albert Einsten, na unidade de radiologia intervencionista.

O tratamento do mioma pela embolização, é uma técnica onde colocamos um tubo na virilha e injetamos pequenas partículas que fecham os vasos que levam sangue para o seu mioma. Assim, vamos avaliar como seu ovário e a parte interna do útero respondem a este tratamento.

A senhora será submetida ao tratamento após ter recibo anestesia na coluna e colocação de sonda na bexiga.

O médico irá colocar o tubo na virilha direita e através de exame de raio $X$ vai guiar este tubo até os vasos que nutrem o seu mioma.

Após o tratamento será feito curativo e a senhora não poderá mexer as pernas por período de 6 horas. A senhora ficará na enfermaria da ginecologia recebendo medicamento para dor, vômitos e febre se assim for necessário.

4 - Descrição dos desconfortos e riscos esperados nos procedimentos dos itens 2 e 3 ;

A senhora pode sentir dor na barriga, vômitos e um pouco de febre. Pode ser que no lugar da colocação do tubo tenha inchaço e dor que irradia para perna. Conforme necessidade a senhora receberá comprimidos para estes sintomas A senhora pode ter infecção no útero, e nesta situação a senhora sentirá febre alta, dor forte no pé da barriga e corrimento com cheiro forte, devendo nesta situação procurar o hospital. Em casos de complicação, diagnosticado durante o procedimento poderá ser realizado cirurgia convencional.

5 - Benefícios para o participante (Por exemplo: Não há benefício direto para o participante... Trata-se de estudo experimental testando a hipótese de que....... Somente no final do estudo poderemos concluir a presença de algum benefício...;

A principal vantagem deste tratamento é não precisar cortar a barriga para tratar os miomas, assim a senhora continuará com seu útero, menstruando normalmente e sem cólica, podendo voltar ao seu trabalho assim que possível.

A retirada definitiva do útero ou cirurgia para tirar os miomas sem tirar o útero é uma opção a embolização.

6 - Relação de procedimentos alternativos que possam ser vantajosos, pelos quais o paciente pode optar;

Não se aplica

7 - Garantia de acesso: em qualquer etapa do estudo, você terá acesso aos profissionais responsáveis pela pesquisa para esclarecimento de eventuais dúvidas. O principal investigador é o Prof. Dr. Marcos de Lorenzo Messina que pode ser encontrado no endereço Rua Dr. Enéas de Carvalho Aguiar, 255, Hospital das Clínicas da Faculdade de 
Medicina da Universidade de São Paulo, Departamento de Ginecologia. Tel: 31671512. Se você tiver alguma consideração ou dúvida sobre a ética da pesquisa, entre em contato com o Comitê de Ética em Pesquisa (CEP) - Rua Ovídio Pires de Campos, 225 - 5a andar - tel: 3069-6442 ramais 16, 17, 18 ou 20, FAX: 3069-6442 ramal 26 - E-mail: cappesq@hcnet.usp.br

08 - É garantida a liberdade da retirada de consentimento a qualquer momento e deixar de participar do estudo, sem qualquer prejuízo à continuidade de seu tratamento na Instituição;

09 - Direito de confidencialidade - As informações obtidas serão analisadas em conjunto com outros pacientes, não sendo divulgado a identificação de nenhum paciente; 10 - Direito de ser mantido atualizado sobre os resultados parciais das pesquisas, quando em estudos abertos, ou de resultados que sejam do conhecimento dos pesquisadores;

11 - Despesas e compensações: não há despesas pessoais para o participante em qualquer fase do estudo, incluindo exames e consultas. Também não há compensação financeira relacionada à sua participação. Se existir qualquer despesa adicional, ela será absorvida pelo orçamento da pesquisa.

12 - Em caso de dano pessoal, diretamente causado pelos procedimentos ou tratamentos propostos neste estudo (nexo causal comprovado), o participante tem direito a tratamento médico na Instituição, bem como às indenizações legalmente estabelecidas. 13 - Compromisso do pesquisador de utilizar os dados e o material coletado somente para esta pesquisa.

Acredito ter sido suficientemente informado a respeito das informações que li ou que foram lidas para mim, descrevendo o estudo Uso da ressonância nuclear magnética da pelve como fator preditivo de sucesso clínico, em pacientes submetidas à embolização do mioma uterino.

Eu discuti com o Prof. Dr. Marcos de Lorenzo Messina sobre a minha decisão em participar nesse estudo. Ficaram claros para mim quais são os propósitos do estudo, os procedimentos a serem realizados, seus desconfortos e riscos, as garantias de confidencialidade e de esclarecimentos permanentes. Ficou claro também que minha participação é isenta de despesas e que tenho garantia do acesso a tratamento hospitalar quando necessário. Concordo voluntariamente em participar deste estudo e poderei retirar 0 meu consentimento a qualquer momento, antes ou durante o mesmo, sem penalidades ou prejuízo ou perda de qualquer benefício que eu possa ter adquirido, ou no meu atendimento neste Serviço.

Assinatura do paciente/representante legal

Data

Nome

Assinatura da testemunha

Data

Nome

Para casos de pacientes menores de 18 anos, analfabetos, semi-analfabetos ou portadores de deficiência auditiva ou visual.

(Somente para o responsável do projeto

Declaro que obtive de forma apropriada e voluntária o Consentimento Livre e Esclarecido deste paciente ou representante legal para a participação neste

Data estudo.

Assinatura do responsável pelo estudo 
Anexo -3 - Avaliação da intensidade de dor e sangramento, relacionada ao leiomioma uterino

\begin{tabular}{|llll|}
\hline Pontos & Volume & Duração da & Dismenorréia \\
& Menstrual & menstruação & \\
\hline $\mathbf{1}$ & Normal & $3-7$ dias & Ausente \\
\hline $\mathbf{2}$ & Aumentado & $>$ 7 dias & Leve \\
\hline $\mathbf{3}$ & muito aumentado & metrorragia & Incapacitante \\
\hline
\end{tabular}

\section{Volume Menstrual}

-Normal: habitual para a paciente

-Aumentado: volume maior que o habitual sem interferir na qualidade de vida

-Muito aumentado: volume maior que o habitual trazendo prejuízo às atividades cotidianas

Dor

- Ausente: ausência de cólica menstrual

-Leve: cólica menstrual que não interfere nas atividades cotidianas

-Incapacitante: cólica menstrual que impede ou impossibilita a execução das atividades cotidianas 
Anexo - 4 Tabela de valores dos nódulos de leiomioma

\begin{tabular}{|l|l|l|l|l|l|l|l|}
\hline $\mathbf{N}$ & ID & IDADE & ID_NÓDULO & pré_UT_VOLUME & pré_ND_VOLUME & pós_UT_VOL & pós_ND_VOL \\
\hline $\mathbf{1}$ & $\mathbf{1}$ & 40 & N1 & $\mathbf{5 1 4 , 3 1}$ & $\mathbf{1 3 2 , 1 2}$ & $\mathbf{3 1 0}$ & $\mathbf{9 2}$ \\
\hline $\mathbf{2}$ & $\mathbf{1}$ & 40 & $\mathrm{~N} 2$ & $\mathbf{5 1 4 , 3 1}$ & $\mathbf{7 , 5 8}$ & $\mathbf{3 1 0}$ & $\mathbf{1 , 9}$ \\
\hline $\mathbf{3}$ & $\mathbf{1}$ & 40 & N3 & $\mathbf{5 1 4 , 3 1}$ & $\mathbf{0 , 5 0}$ & $\mathbf{3 1 0}$ & $\mathbf{0 , 0 3}$ \\
\hline $\mathbf{4}$ & $\mathbf{1}$ & 40 & N4 & $\mathbf{5 1 4 , 3 1}$ & $\mathbf{3 , 7 6}$ & $\mathbf{3 1 0}$ & $\mathbf{2 , 1}$ \\
\hline $\mathbf{5}$ & $\mathbf{1}$ & 40 & N5 & $\mathbf{5 1 4 , 3 1}$ & $\mathbf{1 , 1 2}$ & $\mathbf{3 1 0}$ & $\mathbf{0 , 5}$ \\
\hline $\mathbf{6}$ & $\mathbf{2}$ & 41 & N1 & $\mathbf{5 3 3 , 5 0}$ & $\mathbf{1 5 6 , 3 9}$ & $\mathbf{4 6 4}$ & $\mathbf{8 4}$ \\
\hline $\mathbf{7}$ & $\mathbf{2}$ & 41 & N2 & $\mathbf{5 3 3 , 5 0}$ & $\mathbf{6 3 , 1 5}$ & $\mathbf{4 6 4}$ & $\mathbf{4 5}$ \\
\hline $\mathbf{8}$ & $\mathbf{2}$ & 41 & N3 & $\mathbf{5 3 3 , 5 0}$ & $\mathbf{2 , 4 1}$ & $\mathbf{4 6 4}$ & $\mathbf{0 , 1}$ \\
\hline $\mathbf{9}$ & $\mathbf{2}$ & 41 & N4 & $\mathbf{5 3 3 , 5 0}$ & $\mathbf{2 , 6 1}$ & $\mathbf{4 6 4}$ & $\mathbf{0 , 8}$ \\
\hline $\mathbf{1 0}$ & $\mathbf{2}$ & 41 & N5 & $\mathbf{5 3 3 , 5 0}$ & $\mathbf{1 , 9 6}$ & $\mathbf{4 6 4}$ & $\mathbf{0 , 2}$ \\
\hline $\mathbf{1 1}$ & $\mathbf{2}$ & 41 & N6 & $\mathbf{5 3 3 , 5 0}$ & $\mathbf{9 , 4 0}$ & $\mathbf{4 6 4}$ & $\mathbf{4 , 6}$ \\
\hline
\end{tabular}




\begin{tabular}{|c|c|c|c|c|c|c|c|}
\hline 12 & 2 & 41 & N7 & 533,50 & 17,11 & 464 & 6,7 \\
\hline 13 & 2 & 41 & N8 & 533,50 & 22,37 & 464 & 0 \\
\hline 14 & 3 & 41 & N1 & 591,00 & 127,72 & 256 & 14 \\
\hline 15 & 3 & 41 & N2 & 591,00 & 19,88 & 256 & 0 \\
\hline 16 & 3 & 41 & N3 & 591,00 & 4,97 & 256 & 0,3 \\
\hline 17 & 4 & 36 & N1 & 312,22 & 7,23 & 243 & 2,3 \\
\hline 18 & 4 & 35 & N2 & 312,22 & 31,18 & 243 & 18,36 \\
\hline 19 & 4 & 35 & N3 & 312,22 & 15,50 & 243 & 11,08 \\
\hline 20 & 4 & 35 & N4 & 312,22 & 4,07 & 243 & 2,6 \\
\hline 21 & 5 & 38 & N1 & 633,00 & 114,00 & 465 & 53 \\
\hline 22 & 5 & 38 & N2 & 633,00 & 21,50 & 465 & 11,3 \\
\hline 23 & 5 & 38 & N3 & 633,00 & 11,30 & 465 & 4,1 \\
\hline 24 & 5 & 38 & N4 & 633,00 & 2,50 & 465 & 0,8 \\
\hline 25 & 6 & 30 & N1 & 410,00 & 169,00 & 265 & 59 \\
\hline
\end{tabular}




\begin{tabular}{|c|c|c|c|c|c|c|c|}
\hline 26 & 6 & 30 & N2 & 410,00 & 195,10 & 265 & 160 \\
\hline 27 & 6 & 30 & N3 & 410,00 & 6,60 & 265 & 0 \\
\hline 28 & 7 & 33 & N1 & 648,80 & 136,50 & 437,6 & 35,4 \\
\hline 29 & 7 & 33 & N2 & 648,80 & 90,90 & 437,6 & 34,4 \\
\hline 30 & 7 & 33 & N3 & 648,80 & 64,00 & 437,6 & 20,4 \\
\hline 31 & 7 & 33 & N4 & 648,80 & 15,60 & 437,6 & 2,6 \\
\hline 32 & 7 & 33 & N5 & 648,80 & 8,20 & 437,6 & 9,3 \\
\hline 33 & 7 & 33 & N6 & 648,80 & 41,00 & 437,6 & 4,5 \\
\hline 34 & 7 & 33 & N7 & 648,80 & 7,60 & 437,6 & 0,9 \\
\hline 35 & 8 & 41 & N1 & 172,16 & 5,49 & 171 & 0 \\
\hline 36 & 8 & 41 & N2 & 172,16 & 3,91 & 171 & 0,7 \\
\hline 37 & 8 & 41 & N3 & 172,16 & 6,00 & 171 & 0,8 \\
\hline 38 & 9 & 39 & N1 & 302,00 & 63,40 & 210 & 33 \\
\hline 39 & 9 & 39 & N2 & 302,00 & 2,80 & 210 & 0 \\
\hline
\end{tabular}




\begin{tabular}{|c|c|c|c|c|c|c|c|}
\hline 40 & 9 & 39 & N3 & 302,00 & 9,50 & 210 & 6,9 \\
\hline 41 & 9 & 39 & N4 & 302,00 & 2,30 & 210 & 0,4 \\
\hline 42 & 9 & 39 & N5 & 302,00 & 1,90 & 210 & 1 \\
\hline 43 & 10 & 37 & N1 & 635,00 & 130,90 & 517 & 117,6 \\
\hline 44 & 10 & 37 & N2 & 635,00 & 279,60 & 517 & 88 \\
\hline 45 & 10 & 37 & N3 & 635,00 & 25,50 & 517 & 11 \\
\hline 46 & 11 & 31 & N1 & 323,00 & 155,00 & 184 & 78 \\
\hline 47 & 12 & 37 & N1 & 619,00 & 78,96 & 413 & 41,9 \\
\hline 48 & 12 & 37 & N2 & 619,00 & 95,72 & 413 & 18,8 \\
\hline 49 & 12 & 37 & N3 & 619,00 & 20,19 & 413 & 0,3 \\
\hline 50 & 12 & 37 & N4 & 619,00 & 41,56 & 413 & 0,9 \\
\hline 51 & 12 & 37 & N5 & 619,00 & 1,60 & 413 & 1 \\
\hline 52 & 12 & 37 & N6 & 619,00 & 12,08 & 413 & 1,5 \\
\hline 53 & 13 & 39 & N1 & 118,74 & 94,92 & 99 & 72 \\
\hline
\end{tabular}




\begin{tabular}{|c|c|c|c|c|c|c|c|}
\hline 54 & 13 & 39 & N2 & 118,74 & 149,37 & 99 & 88 \\
\hline 55 & 13 & 39 & N3 & 118,74 & 4,00 & 99 & 3,3 \\
\hline 56 & 14 & 38 & N1 & 1180,00 & 515,00 & 611 & 31,1 \\
\hline 57 & 14 & 38 & N2 & 1180,00 & 14,50 & 611 & 8,6 \\
\hline 58 & 14 & 38 & N3 & 1180,00 & 2,22 & 611 & 1,19 \\
\hline 59 & 15 & 41 & N1 & 225,00 & 11,18 & 160 & 0 \\
\hline 60 & 15 & 41 & N2 & 225,00 & 9,20 & 160 & 6,6 \\
\hline 61 & 15 & 41 & N3 & 225,00 & 21,50 & 160 & $\overline{18,4}$ \\
\hline 62 & 15 & 41 & N4 & 225,00 & 6,56 & 160 & 6,6 \\
\hline 63 & 16 & 37 & N1 & 1051,00 & 290,00 & 803 & 239 \\
\hline 64 & 16 & 37 & N2 & 1051,00 & 118,00 & 803 & 132 \\
\hline 65 & 16 & 37 & N3 & 1051,00 & 98,00 & 803 & 54 \\
\hline 66 & 16 & 37 & N4 & 1051,00 & 150,00 & 803 & 50,5 \\
\hline 67 & 16 & 37 & N5 & 1051,00 & 62,00 & 803 & 16,3 \\
\hline
\end{tabular}




\begin{tabular}{|c|c|c|c|c|c|c|c|}
\hline 68 & 16 & 37 & N6 & 1051,00 & 41,00 & 803 & 21,4 \\
\hline 69 & 16 & 37 & N7 & 1051,00 & 1,80 & 803 & 0 \\
\hline 70 & 17 & 34 & N1 & 1320,00 & 50,50 & 535 & 0 \\
\hline 71 & 17 & 34 & N2 & 1320,00 & 71,30 & 535 & 0 \\
\hline 72 & 17 & 34 & N3 & 1320,00 & 83,00 & 535 & 0 \\
\hline 73 & 17 & 34 & N4 & 1320,00 & 84,00 & 535 & 0 \\
\hline 74 & 17 & 34 & N5 & 1320,00 & 40,00 & 535 & 0 \\
\hline 75 & 18 & 38 & N1 & 633,00 & 24,80 & 243 & 2,6 \\
\hline 76 & 18 & 38 & N2 & 633,00 & 3,30 & 243 & 1 \\
\hline 77 & 18 & 38 & N3 & 633,00 & 23,50 & 243 & 4,3 \\
\hline 78 & 18 & 38 & N4 & 633,00 & 4,10 & 243 & 3,1 \\
\hline 79 & 18 & 38 & N5 & 633,00 & 4,70 & 243 & 4,1 \\
\hline 80 & 18 & 38 & N7 & 633,00 & 3,40 & 243 & 1,2 \\
\hline 81 & 19 & 37 & N1 & 1045,00 & 87,00 & 847 & 35 \\
\hline
\end{tabular}




\begin{tabular}{|c|c|c|c|c|c|c|c|}
\hline 82 & 19 & 37 & $\mathrm{~N} 2$ & 1045,00 & 75,00 & 847 & 37 \\
\hline 83 & 19 & 37 & N3 & 1045,00 & 83,00 & 847 & 38 \\
\hline 84 & 19 & 37 & N4 & 1045,00 & 32,00 & 847 & 21 \\
\hline 85 & 19 & 37 & N5 & 1045,00 & 51,00 & 847 & 12 \\
\hline 86 & 19 & 37 & N6 & 1045,00 & 23,00 & 847 & 8 \\
\hline 87 & 19 & 37 & N7 & 1045,00 & 146,00 & 847 & 53 \\
\hline 88 & 20 & 30 & N1 & 546,00 & 83,00 & 324 & 39 \\
\hline 89 & 20 & 30 & N2 & 546,00 & 57,00 & 324 & 16 \\
\hline 90 & 20 & 30 & N3 & 546,00 & 7,60 & 324 & 6,5 \\
\hline 91 & 20 & 30 & N4 & 546,00 & 3,60 & 324 & 0,3 \\
\hline 92 & 20 & 30 & N5 & 546,00 & 2,60 & 324 & 0,3 \\
\hline 93 & 21 & 32 & N1 & 521,00 & 210,00 & 193 & 115 \\
\hline 94 & 21 & 32 & N2 & 521,00 & 35,00 & 193 & 17 \\
\hline 95 & 21 & 32 & N3 & 521,00 & 3,50 & 193 & 1,6 \\
\hline
\end{tabular}




\begin{tabular}{|c|c|c|c|c|c|c|c|}
\hline 96 & 22 & 38 & N1 & 395,00 & 63,50 & 275 & 37,3 \\
\hline 97 & 22 & 38 & N2 & 395,00 & 10,00 & 275 & 8 \\
\hline 98 & 23 & 38 & N1 & 303,00 & 8,80 & 188 & 7 \\
\hline 99 & 23 & 38 & N2 & 303,00 & 11,40 & 188 & 7,4 \\
\hline 100 & 23 & 38 & N3 & 303,00 & 9,20 & 188 & 6,3 \\
\hline 101 & 23 & 38 & N4 & 303,00 & 5,80 & 188 & 1,7 \\
\hline 102 & 23 & 38 & N5 & 303,00 & 12,40 & 188 & 7 \\
\hline 103 & 24 & 35 & N1 & 1660,00 & 35,80 & 953 & 5,8 \\
\hline 104 & 24 & 35 & N2 & 1660,00 & 14,00 & 953 & 4,3 \\
\hline 105 & 24 & 35 & N3 & 1660,00 & 9,30 & 953 & 0,7 \\
\hline 106 & 24 & 35 & N4 & 1660,00 & 20,80 & 953 & 0,5 \\
\hline 107 & 24 & 35 & N5 & 1660,00 & 10,70 & 953 & 0,5 \\
\hline 108 & 24 & 35 & N6 & 1660,00 & 3,20 & 953 & 4,5 \\
\hline 109 & 24 & 35 & N7 & 1660,00 & 1,30 & 953 & 0,5 \\
\hline
\end{tabular}




\begin{tabular}{|c|c|c|c|c|c|c|c|}
\hline 110 & 25 & 34 & N1 & 2030,00 & 465,00 & 1634 & 449,5 \\
\hline 111 & 25 & 34 & N2 & 2030,00 & 465,00 & 1634 & 66 \\
\hline 112 & 26 & 45 & N1 & 687,00 & 35,60 & 278 & 39 \\
\hline 113 & 26 & 45 & N2 & 687,00 & 22,60 & 278 & 17 \\
\hline 114 & 26 & 45 & N3 & 687,00 & 21,20 & 278 & 16,9 \\
\hline 115 & 27 & 35 & N1 & 432,00 & 106,00 & 257 & 76 \\
\hline 116 & 27 & 35 & N2 & 432,00 & 32,00 & 257 & 23,5 \\
\hline 117 & 27 & 35 & N3 & 432,00 & 17,30 & 257 & 6,3 \\
\hline 118 & 27 & 35 & N4 & 432,00 & 5,50 & 257 & 1,9 \\
\hline 119 & 28 & 32 & N1 & 1098,00 & 703,00 & 71 & 0 \\
\hline 120 & 29 & 44 & N1 & 2136,60 & 93,20 & 872 & 41,1 \\
\hline 121 & 29 & 44 & N2 & 2136,60 & 68,80 & 872 & 54,5 \\
\hline 122 & 29 & 44 & N3 & 2136,60 & 55,10 & 872 & 55,1 \\
\hline 123 & 29 & 44 & N4 & 2136,60 & 73,80 & 872 & 38,3 \\
\hline
\end{tabular}




\begin{tabular}{|c|c|c|c|c|c|c|c|}
\hline 124 & 29 & 44 & N5 & 2136,60 & 52,40 & 872 & 29,9 \\
\hline 125 & 29 & 44 & N6 & 2136,60 & 6,10 & 872 & 6 \\
\hline 126 & 30 & 33 & N1 & 1555,00 & 702,00 & 754 & 408 \\
\hline 127 & 31 & 33 & N1 & 665,80 & 197,70 & 282 & 42,2 \\
\hline 128 & 31 & 33 & $\mathrm{~N} 2$ & 665,80 & 15,10 & 282 & 6,8 \\
\hline 129 & 31 & 33 & N3 & 665,80 & 12,90 & 282 & 9,4 \\
\hline 130 & 31 & 33 & N4 & 665,80 & 3,80 & 282 & 2,22 \\
\hline 131 & 32 & 33 & N1 & 624,60 & 331,10 & 530 & 280,8 \\
\hline 132 & 32 & 33 & $\mathrm{~N} 2$ & 624,60 & 67,40 & 530 & 62,2 \\
\hline 133 & 32 & 33 & N3 & 624,60 & 2,70 & 530 & 2,5 \\
\hline 134 & 33 & 40 & N1 & 385,00 & 5,00 & 156 & 1,8 \\
\hline 135 & 33 & 40 & $\mathrm{~N} 2$ & 385,00 & 4,20 & 156 & 0,4 \\
\hline 136 & 34 & 39 & N1 & 459,00 & 81,60 & 316,8 & 59 \\
\hline 137 & 34 & 39 & N2 & 459,00 & 12,00 & 316,8 & 12,6 \\
\hline
\end{tabular}




\begin{tabular}{|c|c|c|c|c|c|c|c|}
\hline 138 & 34 & 39 & N3 & 459,00 & 12,60 & 316,8 & 12,6 \\
\hline 139 & 35 & 40 & N1 & 943,00 & 274,00 & 430 & 0 \\
\hline 140 & 35 & 40 & N2 & 943,00 & 9,20 & 430 & 0 \\
\hline 141 & 36 & 33 & N1 & 154,00 & 17,00 & 147 & 17 \\
\hline 142 & 36 & 33 & N2 & 155,00 & 6,00 & 147 & 6 \\
\hline 143 & 37 & 40 & N1 & 312,00 & 19,00 & 198 & 4,5 \\
\hline 144 & 38 & 41 & N1 & 460,00 & 136,00 & 192 & 46 \\
\hline 145 & 39 & 36 & N1 & 328,00 & 89,00 & 256 & 55 \\
\hline 146 & 39 & 36 & N2 & 328,00 & 7,50 & 256 & 6,2 \\
\hline 147 & 40 & 39 & N1 & 624,00 & 380,00 & 608 & 290 \\
\hline 148 & 41 & 40 & N1 & 154,00 & 5,40 & 64 & 4,8 \\
\hline 149 & 42 & 40 & N1 & 400,00 & 41,00 & 244 & 35 \\
\hline 150 & 42 & 40 & N2 & 400,00 & 24,00 & 244 & 10 \\
\hline 151 & 43 & 40 & N1 & \begin{tabular}{|l|}
391,00 \\
\end{tabular} & 26,00 & 170 & 12,6 \\
\hline
\end{tabular}




\begin{tabular}{|c|c|c|c|c|c|c|c|}
\hline 152 & 43 & 40 & N2 & 391,00 & 7,40 & 170 & 0 \\
\hline 153 & 43 & 40 & N3 & 391,00 & 5,80 & 170 & 0 \\
\hline 154 & 44 & 37 & N1 & 293,40 & 11,00 & 152 & 0 \\
\hline 155 & 44 & 37 & N2 & 293,40 & 13,70 & 152 & 0 \\
\hline 156 & 45 & 41 & N1 & 201,00 & 22,50 & 102 & 17 \\
\hline 157 & 45 & 41 & N2 & 201,00 & 11,30 & 102 & 4,3 \\
\hline 158 & 46 & 39 & N1 & 165,70 & 13,60 & 160 & 6,5 \\
\hline 159 & 46 & 39 & N2 & 165,70 & 15,40 & 160 & 7 \\
\hline 160 & 46 & 39 & N3 & 165,70 & 6,90 & 160 & 1,2 \\
\hline 161 & 46 & 39 & N4 & 165,70 & 7,30 & 160 & 4 \\
\hline 162 & 47 & 39 & N1 & 456,00 & 14,00 & 256 & 0 \\
\hline 163 & 47 & 39 & $\mathrm{~N} 2$ & 456,00 & 9,10 & 256 & 10 \\
\hline 164 & 48 & 39 & N1 & 305,00 & 352,00 & 164 & 125 \\
\hline 165 & 48 & 39 & N2 & 305,00 & 77,20 & 164 & 34 \\
\hline
\end{tabular}




\begin{tabular}{|c|c|c|c|c|c|c|c|}
\hline 166 & 48 & 39 & N3 & 305,00 & 40,10 & 164 & 14,7 \\
\hline 167 & 48 & 39 & N4 & 305,00 & 64,10 & 164 & 0 \\
\hline 168 & 48 & 39 & N5 & 305,00 & 28,50 & 164 & $\overline{10,4}$ \\
\hline 169 & 48 & 39 & N6 & 305,00 & 2,70 & 164 & 0 \\
\hline 170 & 49 & 33 & N1 & 629,70 & 79,20 & 287 & 19 \\
\hline 171 & 49 & 33 & N2 & 629,70 & 32,60 & 287 & 23 \\
\hline 172 & 49 & 33 & N3 & 629,70 & 24,40 & 287 & 12,3 \\
\hline 173 & 49 & 33 & N4 & 629,70 & 30,00 & 287 & 14 \\
\hline 174 & 49 & 33 & N5 & 629,70 & 21,10 & 287 & 11 \\
\hline 175 & 50 & 39 & N1 & 530,00 & 336,00 & 229 & 207 \\
\hline 176 & 50 & 39 & N2 & 530,00 & 215,00 & 229 & 135 \\
\hline 177 & 50 & 39 & N3 & 530,00 & 103,00 & 229 & 56 \\
\hline 178 & 50 & 39 & N4 & 530,00 & 113,00 & 229 & 79 \\
\hline 179 & 50 & 39 & N5 & 530,00 & 88,00 & 229 & 20 \\
\hline
\end{tabular}


N

ID

ID_NÓDULO

pré_UT_VOLUME

pré_ND_VOLUME

pós_UT_VOL

pós_ND_VOL ordem na planilha

ordem por pacente

número do nódulo por paciente

volume útero pré-embolização

volume nódulo pré-embolização

volume útero pós-embolização

volume nódulo pós-embolização 


\section{8 - REFERÊNCIAS ${ }^{1}$}

ACOG Committee on Gynecologic Practice. Obstet Gynecol 2009;114:11561158.

Agência nacional de Saúde Suplementar http://www.ans.gov.br/index.php/aans/sala-de-noticias-ans/consumidor/1261-rol-de-procedimentos-2012, acessado em 25/02/2012.

Alelez JP. Single-stage total hysteroscopic myomectomies: indications, techniques and results. Fertil Steril. 1995; 63:703-8.

Bernardo A, Gomes MT, Castro RA, Girão MJ, Bonduki CE, Yokoyama CA. Impact of the myoma arterial embolization by uterine volume, diameter myoma greater and in the ovarian function. Rev Bras Ginecol Obstet. 2011;33(8):201-6.

Bonduki CE, Feldner PC Jr, da Silva J, Castro RA, Sartori MG, Girão MJ. Pregnancy after uterine arterial embolization. Clinics. 2011;66(5):807-10.

Bozzini N, Rodrigues CJ, Petti DA, Bevilacqua RG, Gonçalves SP,Pinotti JA. Effects of treatment with gonadotrophin releasing hormone agonist on the uterine leiomyomata structure. Acta Obstet Gynnecol Scand. 2003;82:330-4.

Bradley LD. Uterine fibroid embolization: a viable alternative to hysterectomy. Am J Obstet Gynecol. 2009;201(2):127-35.

Burn PR, McCall JM, Chinn RJ, Vashisht A, Smith JR, Healy JC. Uterine fibroleiomyoma: MR imaging appearances before and after embolization of uterine arteries. Radiology. 2000;21(3):720-34.

Candiani GB, Fedele L, Parazzini F, Villa L. Risk of recurrence after myomectomy. Br J Obstet Gynaecol. 1991;98:385-9.

Cardozo ER, Clark AD, Banks NK, Henne MB, Stegmann BJ, Segars JH. The estimated anual cost of uterine leiomyomata in the United States. Am J Obstet Gynecol. 2012;206:211.e1-9

\footnotetext{
${ }^{1}$ Esta Tese está de acordo com as seguintes normas, em vigor no momento desta publicação: Referências: adaptado de International Commitee of Medical Journals Editors (Vancouver) Universidade de São Paulo. Faculdade de Medicina. Serviço de Biblioteca e Documentação. Guia de apresentação de dissertações, teses e monografias. Elaborado por Anneliese Carneiro da Cunha, Maria Julia de A. L. Freddi, Maria F. Crestana, Marinalva de Souza Aragão, Suely Campos Cardoso, Valéria Vilhena. $2^{\mathrm{a}}$ ed. São Paulo: Serviço de Biblioteca e Documentação; 2005.

Abreviaturas dos títulos dos periódicos de acordo com List of Journals Indexed in Index Medicus.
} 
Chiesa AG, Hart WR. Uterine artery embolization of leiomyomas with trisacryl gelatin microspheres (TGM): pathologic features and comparison with polyvinyl alcohol emboli. [Case Reports. Journal Article] International Journal of Gynecological Pathology. 2004;23(4):386-92.

Chua GC. Wilsher M. Young MP. Manyonda I. Morgan R. Belli AM. Comparison of particle penetration with non-spherical polyvinyl alcohol versus trisacryl gelatin microspheres in women undergoing premyomectomy uterine artery embolization. Clinical Radiology. 2005;60(1):116-22.

Cicinelli E, Romano F, Anastasio PS, Blasi N, Parisi C, Galantino P. Transabdominal sonohysterography, transvaginal sonography, and hysteroscopy in the evaluation of submucous myomas. Obst Gynecol. 1995; 85:42-7.

Cramer SF, Patel A. The frequency of uterine leiomyomas. Am J Clin Pathol. 1990;94(4):435-8.

Cura M, Cura A, Bugnone A. Role of magnetic resonanse imaging in patient selection for uterine artery embolization. Acta Radiol. 2006;47(10):1105-14.

Day Baird D, Dunson DB, Hill MC, Cousins D, Schectman JM. High cumulative incidence of uterine leiomyoma in black and white women: ultrasound evidence. Am J Obstet Gynecol. 2003;188(1):100-7.

De Souza NM, Williams AD. Uterine arterial embolization for leiomyomas: perfusion and volume changes at MR imaging and relation to clinical outcome. Radiology. 2002;222:367-74.

Doridot V, Dubuisson JB, Chapron C, Fauconnier A, Babaki-Fard K. Recurrence of leiomyomata after laparoscopic myomectomy. J Am Assoc Gynecol Laparosc. 2001;8:495-500.

Dueholm M, Lundorf E, Hansen ES, Ladertoug S, Olesen F. Accuracy of magnetic resonance imaging and transvaginal ultrasonography in the diagnosis, mapping and measurement of uterine myomas. Am J Obstet Gynecol. 2002;186:409-15.

Dueholm M, Lundorf E, Sorensen JS, Ledetoug S, Olesen F, Lauresen H. Reproducibility of evaluation of the uterus by transvaginal sonography, hysterographic examination, hysteroscopy and magnetic resonance imaging. Hum Reprod. 2002;17:195-200.

Gabriel-Cox K, Jacobson GF, Armstrong MA, Hung YY, Learman LA. Predictors of histerectomy after artery uterine embolization for leiomyoma. Am J Obstet Gynecol. 2007:196:588e1-588e6. 
Gambone JC, Reiter RC, Lench JB, Moore JG. The impact of a quality assurance process on the frequency and confirmation of rate of hysterectomy. Am J Obstet Gynecol. 1990;163:545-50.

Gliklich RE, Leavy MB, Velentgas P, Campion DM, Mohr P, Sabharwal R, Whicher D, Myers ER, Nicholson VK. Identification of Future Research Needs in the Comparative Management of Uterine Fibroid Disease. A Report on the Priority-Setting Process, Preliminary Data Analysis, and Research Plan. Number 31. March, 2011

Goodwin SC, McLucas B, Lee M, Chen G, Perrella R, Vedantham S, Muir S, Lai A, Sayre JW, DeLeon M. Uterine artery emboliza- tion for the treatment of uterine leiomyomata midterm results. J Vasc Interv Radiol. 1999;10:1159-65.

Gupta JK, Sinha AS, Lumsden MA, Hickey M. Uterine artery embolization for symptomatic uterine fibroids. Cochrane Database Syst Ver 2006; 25(1):CD005073.

Haney AF. Clinical decision making regarding leiomyomata: What we need in the next millennium. Env Health Perspec. 2000;108:supplement 5.

Harman M, Zeteroglu S, Arslan H, Sengul M, Etlik O. Predictive value of magnetic resonanse imaging signal and contrast-enhancement characteistics on post-embolization volume reduction of uterine fibroids. Acta Radiol. 2006; 47(4):427-35.

Hilário SG, Bozzini N, Borsari R, Baracat EC. Action of aromatase inhibitor for treatment of uterine leiomyoma in perimenopausal patients. Fertility and Sterility. 2009;91(1):240-3.

Hovsepian DM, Siskin GP, Bonn J, Cardella JF, Clark TWI, Lampmann LE Miller DL, Omary RA, Pelage JP, Rajan D, Schwartzberg MS, Towbin RB, Walker WJ, Sacks D; CIRSE and SIR Standards of Practice Committees. Quality Improvement Guidelines for Uterine Artery Embolization for Symptomatic Leiomyomata. J Vasc Radiol. 2009;20:S193-S199.

Jha RC, Ascher SM, Imaoka I, Spies JB. Symptomatic fibroleiomyomata: MR imaging of the uterus before and after uterine arterial embolization. Radiology. 2000;217:228-235.

Jung DC, Kim MD, Oh YT, Won JY, Lee DY. Prediction of early response to uterine arterial embolisation of adenomyosis: value of T2 signal intensity ratio of adenomyosis. Eur Radiol. 2012. Online First - acessado em 18/04/2012.

Katsumori T, Nakajima K, Mihara T, Tokuhiro M. Uterine artery embolization using gelatin sponge particles alone for symptomatic uterine fibroids: midterm results. [Journal Article] AJR. American Journal of Roentgenology. 2002;178(1):135-9. 
Keeling AN, Reidy FR. Imaging and treatment of uterine fibroids, including the role of uterine artery embolization. Imaging. 2007:19(4):374-84.

Kim DK, Lee HS, Lee MH, Kim HJ, Cho JH, Cha SH. Long-term results of symptomatic fibroids treated with uterine artery embolization: In conjuction with MR evaluation. Eur J Radiol 2010;73:339-44.

Kim HS, Tsai J, Patra A, Lee JM, Griffith JG, Wallach EE. Effects of uteroovarian anastomoses on clinical outcomes and repeat intervention rates after uterine artery embolization. J Vasc Interv Radiol. 2006;17(5):783-9.

Leibsoln S, D'Ablaing G, Mishell DR, Schlaerth JB. Leiomyosarcoma in a series of hysterectomies performed for presumed uterine leiomyomas. Am J Obstet Gynecol. 1990;162:968-76.

Merrill RM .Hysterectomy surveillance in the United States, 1997 through 2005. Med Sci Monit. 2008;14(1):24-31

Messina ML, Bozzini n, Halbe HW, Pinotti JA. Uterine artery embolization for the treatment of uterine leiomyomata. Int J Gynaecol Obstet. 2002;79(1):116.

Nikolaidis P, Siddiqi AJ, Carr JC, Vogelzang RL, Miller FH, Chrisman HB, Nemcek AA Jr, Omary RA. Incidence of nonviable leiomyomas on contrast material-enhanced pelvic MR imaging in patients referred for uterine artery embolization. J Vasc Interv Radiol. 2005;16(11):1465-71.

Omary RA, Vasireddy S, Chrisman HB, Ryu RK, Pereles FS, Carr JC, Resnick SA, Nemcek AA Jr, Vogelzang RL. The effect of pelvic MR imaging on the diagnosis and treatment of women with presumed symptomatic uterine fibroids. J Vasc Radiol. 2002;13:1149-53.

Othman EE, Al-Hendy A. Molecular genetics and racial disparities of uterine leiomyomas. Best Pract Res Clin Obstet Gynaecol. 2008;22(4):589-601.

Parker WH. Etiology, symptomatology and diagnosis of uterine myomas. Fertil Steril. 2007;87(4):725-36.

Parker WH. The utility of MRI for the susrgical treatment of women with uterine fibroid tumors. Am J Obstet Gynecol. 2012;206(1):31-6.

Pelage JP, Guaou NG, Jha RC, Ascher SM, Spies JB. Uterine fibroid tumors: long-term MR imaging outcome after embolization. Radiology. 2004;230:803-9.

Pinto, Ricardo Augusto de Paula. Tratamento das pacientes sintomáticas portadoras de miomas uterinos através da associação das técnicas de embolização dos miomas e ligadura endovascular das artérias uterinas. 2007. Tese (Doutorado em Radiologia) - Faculdade de Medicina, 
Universidade de São Paulo, São Paulo, 2007. Disponível em: <http://www.teses.usp.br/teses/disponiveis/5/5151/tde-06062007-110430/>. Acessado em: 20-02-2012.

Portal do Ministério da Saúde. Estudos de revisão sistemática concluído. http://portal.saude.gov.br/portal/saude/visualizar_texto.cfm?idtxt=24253 acessado em 25/06/2011.

Portal do Ministério da Saúde. Morbidade Hospitalar do SUS - por local de internação. http://tabnet.datasus.gov.br/cgi/deftohtm.exe?sih/cnv/miuf.def acessado em 05/12/2011.

Portal da Agência Nacional de Saúde - ANS. http://www.ans.gov.br/index.php/a-ans/sala-de-noticias-

ans/consumidor/1261-rol-de-procedimentos-2012, acessado em 25/02/2012.

Projeto Diretrizes da Associação Médica Brasileira, 2002 - Miomatose Uterina. http://www.febrasgo.org.br/arquivos/diretrizes/076.pdf -- Acessado em 25/08/2011.

Prollius A, de Vries C, Loggenberg E, Du Plessis A, Nel M, Wessels PH. Uterine artery embolisation for symptomatic fibroids: the efect of the large uterus in outcome. BJOG. 2004;111:239-42.

Pron G, Cohen M, Soucie J, Garvin G, Vanderburgh L, Bell S. The Ontario Uterine Fibroid Embolization Trial. Parte 1. Baseline patient characteristics, fibroid burden, and impact on life. Fertil Steril. 2003;79:112-9.

Ravina JH, Herbreteau D, Ciraru-Vigneron N, Bouret JM, Houdart E, Aymard A, Merland JJ. Arterial embolisation to treat uterine myomata. Lancet. 1995; 346(8976):671-2.

Rein MS, Friedman AJ, Barbieri RL, Pavelka K, Fletcher JA, Morton CC. Cytogenetic abnormalities in uterine leiomyomata. Obstet Gynecol. 1991;77(6):923-6.

Schwartz SM. Epidemiology of uterine leiomyomata. Clin Obstet Gynecol. 2001;44(2):316-26.

Souza LRMF, Faintuch S, Goldman SM, Louveira MH, Ajzen SA, Szejnfeld J. Avaliacão por ressonância magnética das massas pélvicas. Rev Image. 2003;25(1):5-11.

Spielmann AL, Keogh C, Forster BB, Martin ML, Machan LS. Comparison of $\mathrm{MRI}$ and sonography in the preliminary evaluation for fibroid embolization. AJR Am J Roentgenol. 2006;187:1499-504.

Spies JB, Roth AR, Jha RC, Gomez-Jorge J, Levy EB, Chang TC, Ascher SA. Leiomyomata treated with uterine artery embolization: factors associated 
with successful symptom and imaging outcome. Radiology. 2002;222:4552.(a)

Spies JB, Myers ER, Worthington-Kirsh R, Malgund J, Goodwin S, Mauro M. The fibroid registry: symptom and quality-of-life status 1 year after therapy. Obstet Gynecol. 2005;106:1309-18.(b)

Sipola P, Ruuskanen A, Yawu L, Husso M, Vanninen R, Hippeläinen M, Manninen $\mathrm{H}$. Preinterventional Quantitative Magnetic Resonance Imaging Predicts Uterus and Leiomyoma Size reduction After uterine Artery Embolization. J Magn Reson Imaging. 2010;31:617-24.

Stewart EA, Faur AV, Wise LA, Reilly RJ, Harlow BL. Predictors of subsequent surgery for uterine leiomyomata after abdominal myomectomy. Obstet Gynecol. 2002;99:426.

Stewart EA. Uterine fibroids. Lancet. 2001;357:293-8.

Tomislav S, Josip M, Liana CS, Marko V, Marko J, Ante R, et al. Uterine artery embolization as nonsurgical treatment of uterine myomas. Obstet Gynecol. 2011;2011:489281. Online First. Disponível em: http://www.ncbi.nlm.nih.gov/pmc/articles/PMC3236393/?tool=pubmed. Acessado em 18/01/2012.

Tropeano G, Di Stasi C, Amoroso S, Gualano MR, Bonomo L, Scambia G. Long-term effects of uterine fibroid embolization on ovarian reserve; a prospective cohort study. Fertil Steril. 2010;94(6):2296-300.

Tulandi T, Salamah K. Fertility and Uterine Artery Embolization. Obstet Gynecol. 2010;115(4):857-60.

Van de Kooji SM, Bipat S, Hehenkamp WJK, Ankum WM, Reekers JA. Uterine artery embolization versus surgery in the treatment of symptomatic fibroids: a systematic review and metaanalyses. Am J Obstet Gynecol. 2011;205:317.e1-18.

Van der Kooji, SM, Hehenkamp WJK, Volkers NA, Birnie E, Ankum WM, Reekers JA. Uterine artery embolization vs hysterectomy in the treatment of symptomatic uterine fibroids: 5-year outcome from the randomized EMMY trial. Am J Obstet Gynecol. 2010;203:105e.1-13.

Vercellini P, Maddalena S, DeGiorgi O, Aimi G, Crosignaini PG. Abdominal myomectomy for infertility: a comprehensive review. Hum Reprod. 1998; 13:873-9.

Viswanathan M, Hartmann K, McKoy N, Stuart G, Rankins N, Thieda P, Lux LJ, Lohr KN. Management of uterine fibroids: an update of the evidence. Evid Rep Technol Assess 2007;154:1-122 
Volkers NA, Hehenkamp WJK, Birnie E, Ankum WM, Reekers JA. Uterine artery embolization versus hysterectomy in the treatment of symptomatic uterine fibroids: 2 years outcome from randomized EMMY trial. Am J Obstet Gynecol. 2007;196(6):519-519.

Walker CL., Stewart EA. Uterine fibroids: the elephant in the room. Science. 2005;308:1589-92

Walker WJ, Bratby MJ. Magnetic resonance imaging analysis of fibroid location in women achieving pregnancy after uterine artery embolization. Cardiovasc Intervent Radiol. 2007,30:876-81.

Wallach EE, Vlahos NF. Uterine myomas: an overview of development, clinical features, and management. Obstet Gynecol. 2004;104:393-406.

Walocha JA, Litwin JA, Miodovski AJ. Vascular system of intramural leiomyomata revealed by corrosion casting and scanning electron microscopy. Hum Reprod. 2003;18:1088-93.

Whiteman MK, Hillis SD, Jamieson DJ, Meikle SF, Posner SF, Marchbanks PA. Inpatient hysterectomy surveillance in the United States, 2000-2004. Am J Obstet Gynecol. 2008;198:34.e1-34.e7.

Wu JM, Wechter ME, Geller EJ, Nguyen TV, Visco AG. Hysterectomy rates in the United States, 2003. Obstet Gynecol. 2007;110(5):1091-5.

Yamashita Y, Torashima M, Takahashi M, Tanaka N, Katabuchi H, Miyazaki $\mathrm{K}$, Ito $\mathrm{M}$, Okamura $\mathrm{H}$. Hyperintense uterine leiomyoma at T2-weighted MR imaging: differentiation with dynamic enhanced MR imaging and clinical implications. Radiology. 1993;189:721-25. 